Article

\title{
Fine-Resolution Precipitation Mapping in a Mountainous Watershed: Geostatistical Downscaling of TRMM Products Based on Environmental Variables
}

\author{
Yueyuan Zhang ${ }^{1,2}$, Yungang $\mathrm{Li}^{1,2, *}$ (D), Xuan $\mathrm{Ji}^{1,2}$, Xian Luo ${ }^{1,2}$ and Xue Li ${ }^{1,2}$ \\ 1 Asian International Rivers Center, Yunnan University, Kunming 650091, China; \\ zhangyueyuan1@163.com (Y.Z.); jixuan@ynu.edu.cn (X.J.); luoxian@ynu.edu.cn (X.L.); \\ lixue33333z@126.com (X.L.) \\ 2 Yunnan Key Laboratory of International Rivers and Transboundary Eco-Security, Yunnan University, \\ Kunming 650091, China \\ * Correspondence: ygli@ynu.edu.cn; Tel.: +86-871-6503-4577
}

Received: 7 November 2017; Accepted: 16 January 2018; Published: 17 January 2018

\begin{abstract}
Accurate precipitation data at a high spatial resolution are essential for hydrological, meteorological, and ecological research at regional scales. This study presented a geostatistical downscaling-calibration procedure to derive the high spatial resolution maps of precipitation over a mountainous watershed affected by a monsoon climate. Based on the relationships between precipitation and other environmental variables, such as the Normalized Difference Vegetation Index (NDVI) and digital elevation model (DEM), a regression model with a residual correction method was applied to downscale the Tropical Rainfall Measuring Mission (TRMM) 3B43 product from coarse resolution $(25 \mathrm{~km})$ to fine resolution $(1 \mathrm{~km})$. Two methods, geographical difference analysis (GDA) and geographical ratio analysis (GRA), were used to calibrate the downscaled TRMM precipitation data. Monthly $1 \mathrm{~km}$ precipitation data were obtained by disaggregating $1 \mathrm{~km}$ annual downscaled and calibrated precipitation data using monthly fractions derived from original TRMM data. The downscaled precipitation datasets were validated against ground observations measured by rain gauges. According to the comparison of different regression models and residual interpolation methods, a geographically-weighted regression kriging (GWRK) method was accepted to conduct the downscaling of TRMM data. The downscaled TRMM precipitation data obtained using GWRK described the spatial patterns of precipitation reasonably well at a spatial resolution of $1 \mathrm{~km}$ with more detailed information when compared with the original TRMM precipitation. The results of validation indicated that the GRA method provided results with higher accuracy than that of the GDA method. The final annual and monthly downscaled precipitation not only had significant improvement in spatial resolution, but also agreed well with data from the validation rain gauge stations (i.e., $R^{2}=0.72, R M S E=161.0 \mathrm{~mm}, M A E=127.5 \mathrm{~mm}$, and Bias $=0.050$ for annual downscaled precipitation during 2001 to 2015; and $R^{2}=0.91, R M S E=22.2 \mathrm{~mm}, M A E=13.5 \mathrm{~mm}$, and Bias $=0.048$ for monthly downscaled precipitation during 2001 to 2015). In general, the downscaling-calibration procedure is useful for complex mountainous areas with insufficient ground gauges.
\end{abstract}

Keywords: precipitation; TRMM 3B43; spatial downscaling; calibration; the Red River Basin; China

\section{Introduction}

Precipitation plays a significant role in hydrological and ecological processes as a key component of mass exchange and energy balance [1,2]. The spatial variations of precipitation generally influence vegetation distribution, soil moisture, and surface hydrology [3,4]. Accurate high-spatial-resolution 
precipitation data (HSPD) are crucial for different meteorological and hydrological applications, especially in data-sparse regions. For example, high-resolution estimates of spatial variability in rainfall fields can identify locally intense storms that could lead to floods [5]. Meanwhile, the HSPD can capture more spatially detailed information in drought monitoring when compared to rain gauge observations [6]. In addition, HSPD provides a valuable data source for hydrologic modeling and water resources planning purposes $[7,8]$.

Traditionally, precipitation data are acquired from rain gauges that rely heavily on field observations and might be subject to measurement error and heterogeneities in data collection [9]. The high spatial-temporal variability of precipitation and the relatively sparse distribution of rain gauges makes it difficult to provide fine-resolution precipitation data [10-12]. Various interpolation methods have been applied to map precipitation distribution based on a limited number of gauge data. These methods range from simple techniques such as Thiessen polygons, inverse distance weighting (IDW), or spline $[5,13]$ to complex and computationally intensive approaches, such as geostatistical kriging $[14,15]$. The more complex approaches often consider orographic and/or atmospheric effects and spatial covariance on precipitation occurrences, for example, Parameter-elevation Regressions on Independent Slopes Model (PRISM) [16], Orographic Precipitation Model (OPM) [17], and the Auto-Searched Orographic and Atmospheric Effects Detrended Kriging (ASOADeK) model [18]. These studies have revealed that the choice of an appropriate interpolation method depends on the time step used in the analysis, the density of the precipitation network, the precipitation regime, and the catchment's geomorphologic characteristics [19].

With the development of advanced satellites, remote sensing has become the main tool for estimating precipitation over areas lacking rain gauge networks [20]. In recent years, a series of rainfall datasets have been developed at both the regional and global scales. For example, datasets have been developed by the Global Precipitation Climatology Project (GPCP) [21], the Global Satellite Mapping of Precipitation (GSMaP) project [22], the Climate Hazards Group InfraRed Precipitation with Station data (CHIRPS) [23], the Multi-Source Weighted-Ensemble Precipitation (MSWEP) [24], the Precipitation Estimation from Remotely-Sensed Information using Artificial Neural Networks-Climate Data Record (PERSIANN-CDR) [25], the Tropical Rainfall Measuring Mission (TRMM) [26,27], and the Global Precipitation Measurement (GPM) [28]. Among these satellite precipitation datasets, TRMM has had the specific goal of measuring precipitation over the oceans and tropics. This dataset has resulted in the development of a series of rainfall products in the last two decades, and the spatial resolution obtained has reached $0.25^{\circ} \times 0.25^{\circ}$. TRMM data have been used extensively for inter-disciplined investigations and applications such as land surface modeling [29], drought monitoring [30], and hydrological simulation [31]. However, it is still too coarse when applied to the hydrological study of local basins and regions, which generally need higher-resolution inputs [32]. Thus, a robust downscaling procedure below the pixel resolution is needed to meet the requirement of a high spatial resolution.

Precipitation as a natural phenomenon is related to other environmental variables, such as topography and vegetation. Complex topography causes the perturbation and deformation of atmospheric fluxes that influence precipitation patterns by mechanically altering the wind patterns and microphysical processes, which impact condensation of the precipitable water [33]. Precipitation distribution in mountainous regions strongly depends on the terrain altitude and steepness, as well as the orientation of the slopes [34]. In theory, an increase of elevation could increase the relative humidity of air masses by expansion and cooling as the air masses rise, resulting in precipitation [35]. The precipitation-topography relationship is also largely dependent on the fluctuations of the terrain [36]. For example, the barrier effect on the airflow is also closely related to the aspect of mountains, as well as the direction of the airflow. Aspect is linked to the prevalent wind orientation, thus determining the potential relative water excess or deficit [37]. These orographic alteration processes yield large spatial variations with, in general, enhanced precipitation in the windward side of the mountain barriers and reduced precipitation in the lee side [38]. As for slope, a gradient in the speed of vertical air movements may control the intensity and area of precipitation [39]. Therefore, 
topographic information is useful to downscale the precipitation over mountainous regions. Jia et al. [2] improved downscaling results after the inclusion of elevation data. Guan et al. [40] downscaled the resolution of Next Generation Radar (NEXRAD) from $16 \mathrm{~km}$ to four $\mathrm{km}$ by considering the orographic effects on precipitation distribution. Fang et al. [11] developed a statistical spatial downscaling scheme based on the relationships between precipitation and environmental factors, such as slope, aspect, and terrain roughness extracted from a digital elevation model (DEM), as well as humidity and temperature data from meteorological conditions.

The vegetation response on an annual scale has been found to have a positive relationship with precipitation. Many studies used Normalized Difference Vegetation Index (NDVI) as an independent variable to downscale the coarse TRMM precipitation data [32,36,41-43]. Although the response of NDVI to precipitation usually lagged by two or three months [41,44], it was also feasible to downscale monthly, weekly, or daily satellite precipitation datasets by considering lag time. For example, Quiroz et al. [45] applied wavelet transform analysis using NDVI data to improve daily rainfall estimates at meteorological stations located on the Andean Plateau. Hunink et al. [46] assumed a lag time of one week in the regression models to mimic the response of vegetation to precipitation as well as to estimate spatial distributions of precipitation at a high spatial resolution with a weekly time step in a tropical mountainous region in Ecuador.

Statistical downscaling is a recently developed approach in obtaining the high spatial resolution of variables based on correlations between the variable at a coarse resolution and geospatial predictors at a finer resolution [41]. Great efforts have been made to advance the spatial downscaling algorithms of TRMM precipitation products based on the relationships described above. Immerzeel et al. [32] proposed an algorithm for downscaling TRMM datasets using the regression between precipitation and an NDVI based on the exponential function. Jia et al. [2] developed an algorithm using a multiple linear regression (MLR) model and introduced both NDVI and DEM as independent variables. Furthermore, Alexakis [47] implemented a machine learning algorithm, termed an artificial neural network (ANN), to downscale the TRMM 3B42 precipitation fields from $0.25^{\circ}$ to $1-\mathrm{km}$ spatial resolution. Chen et al. [48] and $\mathrm{Xu}$ et al. [49] constructed a geographically weighted regression (GWR) model to obtain higher resolution precipitation datasets based on the assumption that the relationship of rainfall-geospatial factors varied spatially, but was similar within a region. These studies indicated that the HSPD obtained through downscaling algorithms not only better presented the spatial variability, but had higher accuracy than the original TRMM datasets.

Previous studies have shown that monthly rainfall estimates from the TRMM satellite contained errors ( $\pm 8 \%$ to $\pm 12 \%$ per month) due to discrete temporal sampling. As the TRMM satellite is a low Earth orbiting satellite, its rain sensors sample the regional atmosphere only at discrete time intervals, sometimes missing short duration storms [50]. Moreover, regional sampling errors (approximately $30 \%$ ) could be expected in TRMM rainfall estimates [51,52]. Since all downscaling procedures are based on the original TRMM 3B43 data, these errors would be inevitably introduced into the downscaled precipitation data. Reliable calibration methods combining satellite rainfall data with rainfall data from rain gauge stations (RGS) can greatly improve the accuracy of rainfall estimates [53]. For example, better agreements between downscaled precipitation data and observations from RGS were achieved by using geographical difference analysis (GDA) in the study of Duan and Bastiaanssen [41].

Although a large number of algorithms have been developed and applied for the downscaling of satellite-based precipitation data and improvements in accuracy [36], there exists a challenge to generate accurate precipitation in mountainous watersheds due to the sparse gauge network and high spatial-temporal variability of precipitation. In this study, our main goal was to map annual and monthly precipitation with a high spatial resolution over a mountainous, monsoon driven watershed. More specifically, we had four sub-objectives: (1) to test the applicability of the original TRMM 3B43 V7 precipitation data; (2) to compare three different regression techniques (MLR, ANN, and GWR) of estimating precipitation at a coarse resolution and five different interpolation methods of regression residual, choosing one method with the best performance to downscale TRMM precipitation data; (3) to 
map the annual precipitation at a 1-km resolution based on the integrated downscaling-calibration procedure; and (4) to produce maps of monthly precipitation by disaggregating annual downscaled precipitation data using a simple fraction disaggregation method.

\section{Materials and Methods}

\subsection{Study Area}

The Red River Basin is located in Southwest China, with a geographical location of $22^{\circ} 21^{\prime}-25^{\circ} 36^{\prime} \mathrm{N}$ and $100^{\circ} 07^{\prime}-105^{\circ} 42^{\prime} \mathrm{E}$ (Figure 1). The main stream is $677 \mathrm{~km}$ long and the basin area is approximately $7.6 \times 10^{4} \mathrm{~km}^{2}$. The elevation of the catchment ranges from $79 \mathrm{~m}$ to $3142 \mathrm{~m}$ above sea level, decreasing from the Northwest to the Southeast. The variability of terrain, coupled with the influences of the Indian and East Asian monsoons, means precipitation over the Red River Basin has a complex spatial and temporal variation [54]. The annual average precipitation was approximately $1056 \mathrm{~mm}$, ranging from $854 \mathrm{~mm}$ to $1303 \mathrm{~mm}$. Additionally, about $85 \%$ of the annual precipitation is concentrated in the rainy season (May to October), with less than $15 \%$ of the annual precipitation observed in the dry season (November to April). The mean annual temperature ranges from $15^{\circ} \mathrm{C}$ to $24^{\circ} \mathrm{C}$, with June being the warmest month, and the coldest month being January. The precipitation presents a decreasing trend with a latitude and altitude increase (Figure 2). The vegetation of the Red River Basin consists of broad-leaved evergreen forests, coniferous forests, grasslands, and shrubs. Strong correlations between NDVI and precipitation are found in a previous study [55]. Therefore, it is feasible to develop a spatial downscaling-calibration procedure for low-resolution satellite-based precipitation datasets based on NDVI and terrain factors in this area.

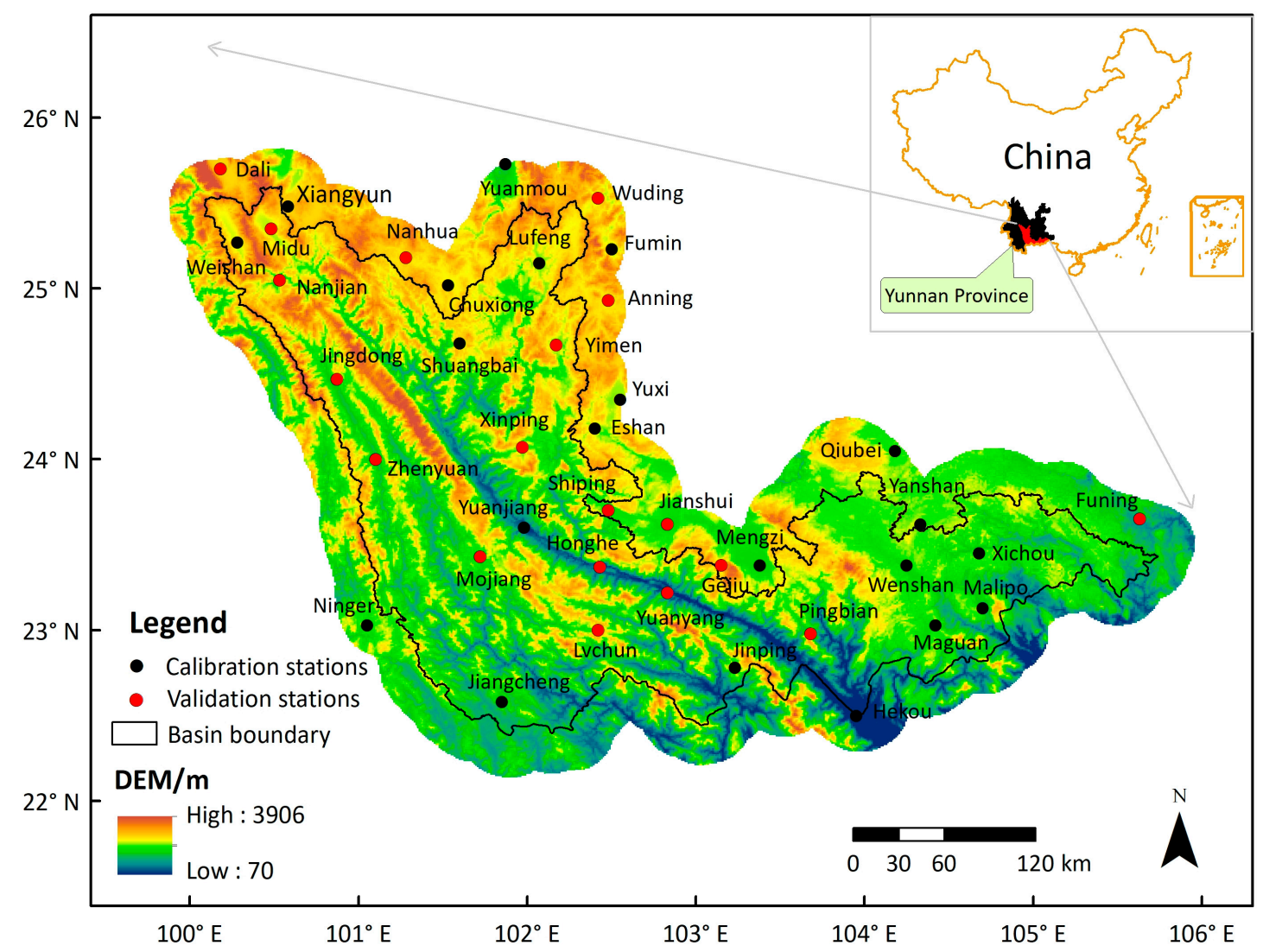

Figure 1. Elevation and distribution of meteorological stations in the Red River Basin. 


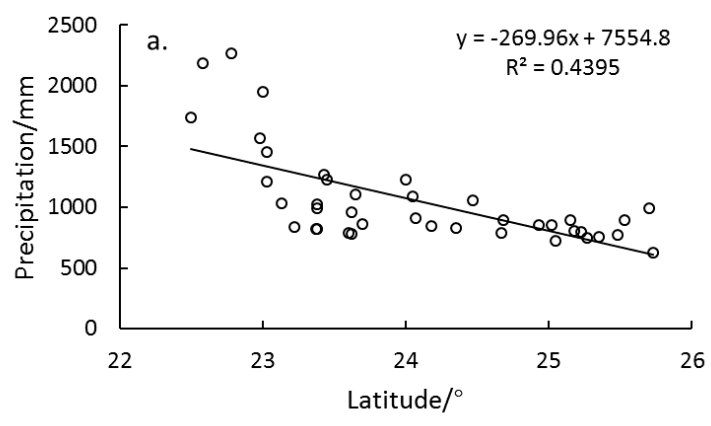

(a)

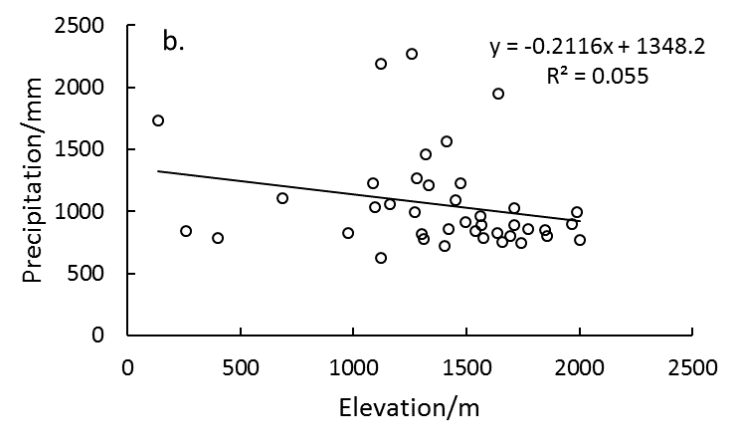

(b)

Figure 2. Scatterplots between annual average precipitation and (a) latitude; (b) elevation for 40 RGS from 2001 to 2015.

\subsection{Data}

\subsubsection{TRMM Precipitation Data}

TRMM is a joint project of the National Aeronautics and Space Administration (NASA) and the Japan Aerospace Exploration Agency (JAXA) launched on 27 November 1997, with the aim of monitoring and studying rainfall in tropical and subtropical regions [26]. TRMM is a research satellite designed to improve our understanding of the distribution and variability of precipitation covering the global region between $50^{\circ} \mathrm{N}$ and $50^{\circ} \mathrm{S}$ and has provided valuable information on rainfall and its associated heat release [27]. The TRMM 3B43 Version 7 dataset used in this study is one of several TRMM precipitation products, containing data from January 2001 to December 2015, with a calendar-month temporal resolution and a $0.25^{\circ} \times 0.25^{\circ}$ spatial resolution. The monthly precipitation data were accumulated to obtain the TRMM annual precipitation.

\subsubsection{NDVI Data}

The Terra Moderate Resolution Imaging Spectroradiometer (MODIS) (NASA, Washington, DC, USA) monthly composite NDVI data of 1-km resolution (MOD13A3, collection v006) spanning the period from January 2001 to December 2015 were downloaded from the NASA Land Processes Distributed Active Archive Center (https:/ /lpdaac.usgs.gov/dataset_discovery/modis). We aggregated the MOD13A3 monthly data into the annual NDVI for 2001-2015.

It should be noted that since the vegetation growth is suppressed or promoted by some land covers (e.g., rivers, lakes, snow and ice, and urban areas), the vegetation data of these land covers were excluded. Additionally, due to the strong influence of farming activities (e.g., irrigation, fertilization, and harvest) on the crop growth, vegetation data of farmland were also excluded [56]. As such, we identified anomalous pixels simply by land use type: pixels categorized as water, wetland, urban, cropland, snow/ice, and barren were identified as anomalies. The detected anomalous pixels were excluded from the original NDVI dataset and then filled with interpolated values using the IDW method to generate an optimized NDVI dataset.

\subsubsection{Land Use Data}

In this study, the land use dataset MCD12Q1 Version 051 (MODIS/Terra+Aqua Land Cover Type Yearly L3 Global 500 m SIN Grid V051) in the period from 2001 to 2013 was used, which has a yearly temporal resolution and a $500 \mathrm{~m} \times 500 \mathrm{~m}$ spatial resolution. MCD12Q1 contains five types of classification that describe the properties of surface coverage derived from the observations of the MODIS sensor. The first surface coverage schema identifies 17 classes defined by the International Geosphere Biosphere Program (IGBP), which was adopted in this study for its wide applications. 
The IGBP classification includes 11 natural vegetation classes, three classes of urbanized lots, and three classes of vegetated ground [57].

The land use dataset was mainly used in this study to identify the outliers of NDVI caused by factors other than precipitation. Since the available MCD12Q1 data spanned 2001 to 2013, we used the year 2013 instead of 2014 and 2015 for identifying outliers of MOD13A3. In addition, due to a mismatch in spatial resolution between the MOD13A3 and MCD12Q1 datasets, the MCD12Q1 dataset was up-scaled to a $1-\mathrm{km}$ resolution.

\subsubsection{DEM Data}

The DEM data were obtained from the NASA Shuttle Radar Topographic Mission (SRTM) [58]. The 90-m DEM was re-sampled at a resolution of 1-km using the pixel averaging method. The variables of slope, aspect, and geolocation (longitude and latitude) data were further extracted from the DEM data.

\subsubsection{Rain Gauge Data}

Monthly precipitation observations obtained from 40 RGS during 2001-2015 were from the Meteorological Agency of Yunnan Province. The locations of the 40 rain gauges are shown in Figure 1. As depicted in Figure 1, the distribution of stations in the study area is dense in the East and relatively sparse in the West. These stations have altitudes from $137 \mathrm{~m}$ to $2003 \mathrm{~m}$, with $85 \%$ between $1000 \mathrm{~m}$ and $2000 \mathrm{~m}$. Figure 3 shows the variation of annual rainfall from 2001 to 2015 . We selected three typical years: 2005, 2001, and 2009 to represent normal, wet, and dry conditions, respectively. These three reference years, as well as the average annual precipitation of 2001-2015, were selected for the downscaling and calibration procedure to evaluate the performance in different climatic conditions.

The rain gauge data was divided into two sample sets. The first set was used to calibrate the downscaled annual precipitation data using calibration methods, and the second set was used for validation. The separation of the RGS for calibration and validation was done as follows: all available fifteen-year period (2001-2015) average annual precipitation from all 40 RGS were first calculated and sorted in a lowest-highest sequence 1-40; then 20 RGS with odd numbers from one to 39, plus number 40, were considered as calibration RGS; the others were validation RGS. This separation allowed the calibration to cover the whole range of precipitation, including the lowest and highest values [41].

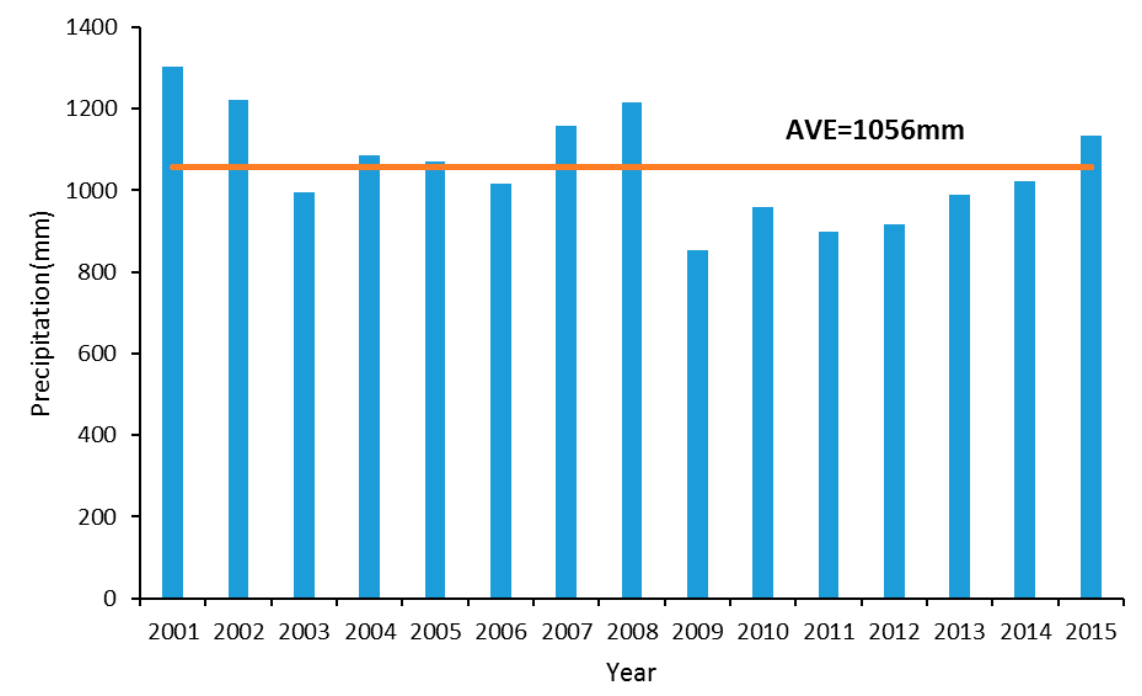

Figure 3. Variation of annual precipitation from 2001 to 2015 over the Red River Basin. 


\subsection{Methods}

A flowchart was provided to illustrate the main steps of the downscaling-calibration and the monthly fraction disaggregation algorithm, which is shown in Figure 4.

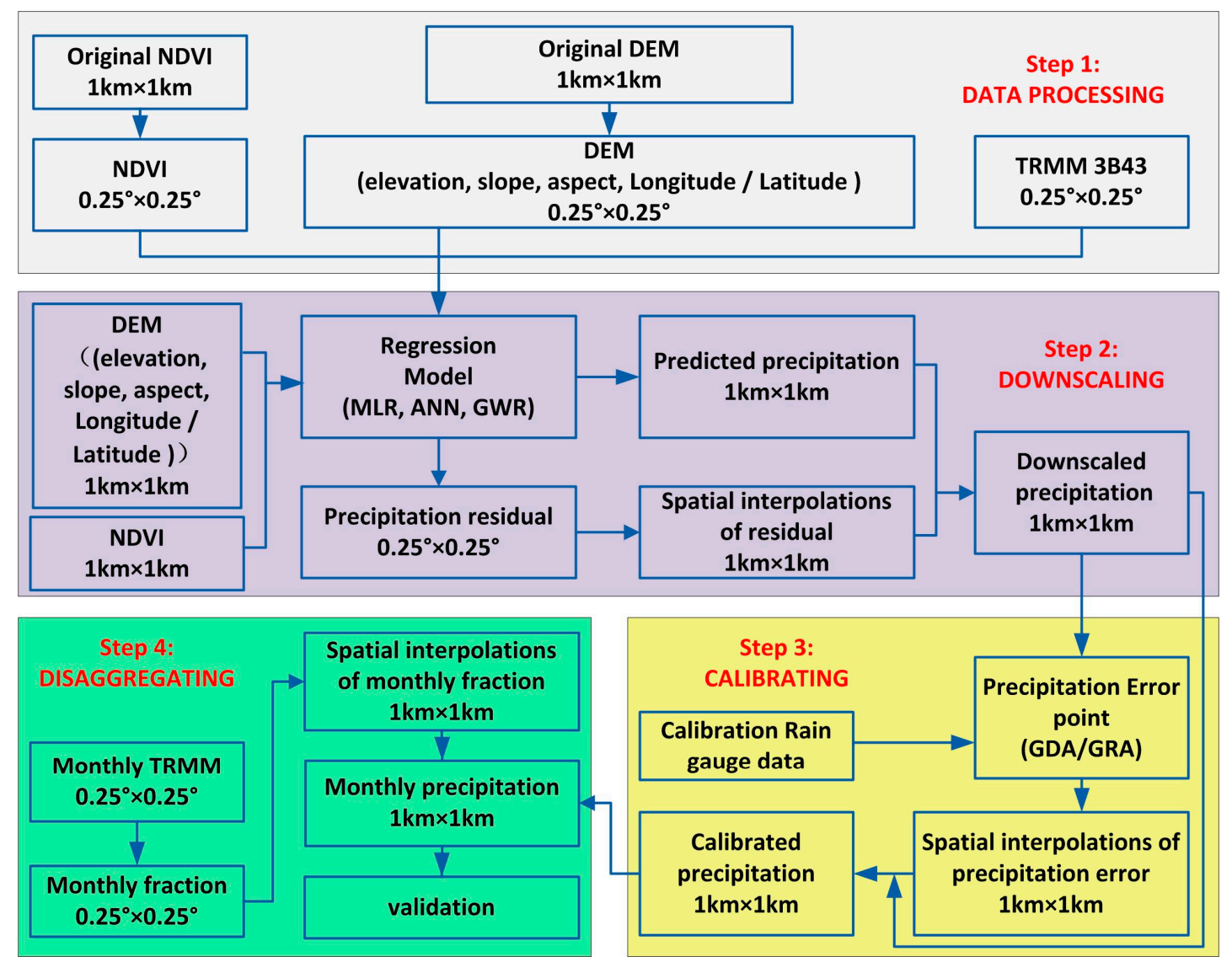

Figure 4. Flowchart of the downscaling-calibration algorithm used in the study.

\subsubsection{Downscaling of Original TRMM 3B43 Precipitation}

We established a hybrid downscaling method using a regression model with residual correction on the basis of previous studies $[2,47,48,59,60]$. Within the hybrid downscaling method, the TRMM precipitation data were decomposed into trend and residual components. First, quantitative relationships between the TRMM data and environmental variables of coarse scale were estimated via regression analysis and used to derive trend component at a fine scale. Second, the residual component, which is the difference between the trend component and the original TRMM data, was then downscaled into a target fine scale via spatial interpolation. The trend and residual components were finally added to generate fine scale precipitation estimates.

The downscaling method was based on two assumptions: (1) precipitation has a spatial relationship with environmental variables, and this relationship can be addressed by established models; and (2) the models established at low spatial resolution can also be used to predict the precipitation at a fine resolution with the higher resolution environmental variables dataset [36]. The specific steps used for downscaling in this study are described as follows:

(1) Original NDVI, elevation, slope, and aspect of 1-km resolution were re-sampled at a resolution of $0.25^{\circ}$ using a pixel averaging method with the geographical coordinates of the center of each $0.25^{\circ}$ grid is also extracted; 
(2) The relationships between the re-sampled independent variables and the TRMM 3B43 V7 precipitation data were established using regression models (i.e., MLR, ANN, GWR), from which we obtained the estimated annual precipitation at the $0.25^{\circ}$ scale;

(3) Geolocations along with the 1-km spatial resolution variables were entered into the model established in Step 2, and a downscaled precipitation of 1-km resolution was achieved;

(4) Residual correction can adjust for the precipitation that cannot be predicted by the models. This adjustment was generated by computing the difference between the estimated precipitation values at the $0.25^{\circ}$ scale and the original TRMM 3B43 data, followed by spatial interpolation into the residual of a 1-km resolution. Five interpolation methods (IDW, spline regularized, spline tension, ordinary kriging, and simple kriging) were applied to the residuals, and cross-validation was used to choose the best interpolation method; and

(5) The corrected downscaled precipitation results were obtained by adding the residual correction term of 1-km resolution to the downscaled precipitation of 1-km resolution.

\subsubsection{Regression Models}

\section{(1) Multiple Linear Regression Model}

The method of analysis used in the multiple linear regression models was the method of least squares, which is a minimization of the sum of the squares of the deviations of the observed response from the fitted response [61]. With precipitation being the dependent variable, we constructed a model that involves both the environmental variables (NDVI, elevation, slope, aspect, longitude, latitude) and their corresponding parameters.

The general form of the model is written as follows:

$$
P=a_{0}+a_{1} x_{1}+a_{2} x_{2}+\ldots+a_{6} x_{6}
$$

where $P$ is precipitation (mm/year); $x_{1}-x_{6}$ are the NDVI, elevation, slope, aspect, longitude, latitude, respectively. Furthermore, $a_{0}-a_{6}$ are the corresponding parameters of the regression function.

We applied stepwise regression to avoid multicollinearity and overfitting of the linear regression equation. For the three reference years and entire time period, the significant correlations between TRMM precipitation and latitude or NDVI were found at the 0.05 significance level, while the other four factors had no significance at the 0.1 level. Therefore, the regression relationship was established based on TRMM precipitation, latitude, and NDVI.

\section{(2) Artificial Neural Network Model}

The theory behind neural networks is based on an attempt to reproduce human learning processes [62]. ANN is an attractive and powerful numerical methodology to map complex relationships between different sets of observed variables [63]. It has been used in different studies to downscale coarse TRMM precipitation data [47,64]. An ANN consists of a collection of different neurons connected to each other. A connection occurs when the status of a neuron, $i$, is one of the inputs for another neuron, $j$, by means of a weight, $W_{i j}$. Individual neurons are often called nodes of the network. The architecture of an ANN is defined by establishing how the individual neurons of the network are connected to each other. To estimate the number of the hidden layer nodes, the equation proposed by Hecht-Nielsen [65] was used as a reference:

$$
N_{g}=2 \times N_{i}+1
$$

where $N_{g}$ is the number of hidden nodes; and $N_{i}$ is the number of input nodes.

The multi-layer perceptron (MLP) neural network was used for the application of the ANN. A three-layer feed forward network consisting of an input layer, one hidden layer, and one output layer was used as the network structure. For example, the network structure of 2001 was 6-16-1. The number of the hidden layer nodes was finally estimated through many simulation experiments. According to 
Equation (2), we first obtained a reference value of 13, then we tried the different numbers around 13, and finally made it 16 , as the network performed best when the number of the hidden layer nodes was 16. The input layer had six neurons, including NDVI, elevation, slope, aspect, longitude, and latitude. The output layer was the precipitation. For the needs of a training procedure, 3000 iterations were set as a threshold to terminate the procedure. The tangent sigmoid function was used for transferring data from one layer to another in the hidden layer. The purelin function was used for transferring data in the output layer. The training and learning function were trainlm and learngdm, respectively. The functions used above are part of Neural Network Toolbox in Matlab (The MathWorks, Natick, MA, USA) [66]. For the samples, approximately two thirds were regarded as training samples, and the other third was used as validation samples. The training process of the ANN consisted of the determination of all the weights of the network based on the observed input/output patterns [47].

(3) Geographically-Weighted Regression Model

GWR is a regional regression method that can be used to investigate the spatially-varying relationship between dependent and explanatory variables [67]. In other words, GWR runs a regression for each location instead of a sole regression for the entire study area [68], which attempts to capture the spatial variation of the relationship by adding the geographical location information into the regression process. The regression model can be rewritten as Equation (3):

$$
y_{i}=\beta_{0}\left(u_{i}, v_{i}\right)+\sum_{k=1}^{p} \beta_{k}\left(u_{i}, v_{i}\right) x_{i k}+\varepsilon_{i} i=1,2, \cdots, n
$$

where $y_{i}$ is the $i$ th observation of the dependent variable; $x_{i k}$ is the $i$ th observation of the $k$ th independent variable; the $\left(u_{i}, v_{i}\right)$ represents the geographical coordinates of $i$ th regression point; and $\beta_{k}\left(u_{i}, v_{i}\right)$ is the $k$ th regression parameter in the $i$ th regression point, which is a function of geographical location. Furthermore, $\varepsilon_{i}$ represents the independent normally distributed error term with zero mean.

The parameters can be estimated by solving the following matrix equation:

$$
\hat{\beta}\left(u_{i}, v_{i}\right)=\left(x^{T}\left(W\left(u_{i}, v_{i}\right)\right) x\right)^{-1} x^{T} W\left(u_{i}, v_{i}\right) y
$$

In this equation, $\hat{\beta}\left(u_{i}, v_{i}\right)$ is the local coefficient to be estimated at location $\left(u_{i}, v_{i}\right) ; x$ and $y$ are the vectors of the explanatory and the dependent variables, respectively; and $W\left(u_{i}, v_{i}\right)$ is the weight matrix, which plays the role of ensuring that closer observations around the $i$ th point carry more weight than observations farther away [48,69]. In this study, the GWR method was conducted using GWR 4.0 software (https:/ / gwrtools.github.io/category/gwr.html) [68].

\subsubsection{Calibration of Downscaled Precipitation}

The GDA calibration method developed by Cheema and Bastiaanssen [53] was used to minimize the difference between the satellite precipitation and the measurements from RGS. Instead of GDA, geographical ratio analysis (GRA) was developed to calibrate the downscaled precipitation. In this process, we compared GDA and GRA using measurements from validation RGS to choose a method that provided results with higher accuracy. The processing steps of GDA/GRA are as follows:

(1) The differences/ratio between the downscaled precipitation values and the measurements from RGS were computed;

(2) The differences/ratio were interpolated into a resolution of $1-\mathrm{km}$ with the interpolation technique; and

(3) The downscaled precipitation was corrected to obtain the final calibrated precipitation by adding/multiplying the differences/ratio term of 1-km resolution. 


\subsubsection{Monthly Fraction Disaggregation from Annual Precipitation}

A simple fraction method derived from original TRMM 3B43 monthly data developed by Duan and Bastiaanssen [41] was used to disaggregate downscaled-calibrated annual 1-km precipitation maps into maps at monthly time steps. The procedure was as follows:

(1) The monthly fractions of $0.25^{\circ}$, which were used to disaggregate the annual precipitation, were defined as:

$$
\text { Fraction }_{i}=\mathrm{TRMMo}_{i} / \sum_{i=1}^{12} \mathrm{TRMMo}_{i}
$$

where the $T R M M o_{i}$ represents the precipitation that occurs during the $i$ th month as estimated from the original TRMM 3B43 product; and the denominator is the annual total value.

(2) The $0.25^{\circ}$ fractions were further interpolated into a spatial resolution of 1-km which was consistent with the downscaled-calibrated annual precipitation using an interpolation method;

(3) The annual downscaled precipitation values at $1-\mathrm{km}$ resolution were disaggregated into monthly-downscaled precipitation values by multiplying the fraction values of $1-\mathrm{km}$ resolution.

\subsubsection{Validation}

The validation in this study included three steps. First, the predicted annual precipitation obtained using three regression models were compared with the original TRMM estimates at $0.25^{\circ}$ resolution. Four metrics, the coefficient of determination $\left(R^{2}\right)$, the root mean square error (RMSE), the mean absolute error $(M A E)$, and the Bias, were used to evaluate the results. They were defined as follows:

$$
\begin{gathered}
R^{2}=\frac{\left[\sum_{i=1}^{n}\left(O_{i}-\bar{O}\right)\left(P_{i}-\bar{P}\right)\right]^{2}}{\sum_{i=1}^{n}\left(O_{i}-\bar{O}\right)^{2} \sum_{i=1}^{n}\left(P_{i}-\bar{P}\right)^{2}} \\
R M S E=\sqrt{\frac{\sum_{i=1}^{n}\left(O_{i}-P_{i}\right)^{2}}{n}} \\
M A E=\frac{\sum_{i=1}^{n}\left|O_{i}-P_{i}\right|}{n} \\
\text { Bias }=\frac{\sum_{i=1}^{n} P_{i}}{\sum_{i=1}^{n} O_{i}}-1
\end{gathered}
$$

where $O$ and $P$ represent the original TRMM precipitation and predicted precipitation of models at $0.25^{\circ}$ resolution, respectively.

Second, leave-one-out cross validation (LOOCV) was used to compare the residual results of different interpolation methods. The LOOCV method removes one point every time, and then predicts the value of this point using the remaining points until all the points were iterated [70]. Two indicators (RMSE and MAE) were calculated based on the predicted values and the original values of all the points to evaluate the interpolation methods.

Third, the accuracy of the final downscaled precipitation was further validated against the measurements from RGS, based on the $R^{2}, R M S E, M A E$, and Bias. The rain gauge data not used for calibration were used to validate the final downscaled results.

\section{Results}

\subsection{Comparison between TRMM and Station-Based Observed Precipitation}

The applicability of the original TRMM 3B43 V7 was tested using measurements from 34 RGS, which are not included in the Global Precipitation Climatology Centre (GPCC) gauge network used in 3B43 ground calibrations. Figure 5 shows plots of the original TRMM precipitation against rain gauge measurements at multi-time scale from 2001 to 2015. From Figure 5, a significant correlation was 
found between the two datasets during the dry season, wet season, and whole year. The correlation coefficients reached 0.87 (dry season), 0.84 (wet season), and 0.91 (whole year), respectively, which all passed the 0.01 level of significance test. These results indicated an obvious linear correlation and consistency between TRMM precipitation and rain gauge data. In terms of bias, the dry season, wet season, and whole year were 0.091, 0.057, and 0.062, respectively, which means that the precipitation was overestimated by TRMM 3B43 when compared with observations from RGS. On the whole, there was a strong applicability of the original TRMM 3B43 data in the estimation of precipitation over the Red River Basin.

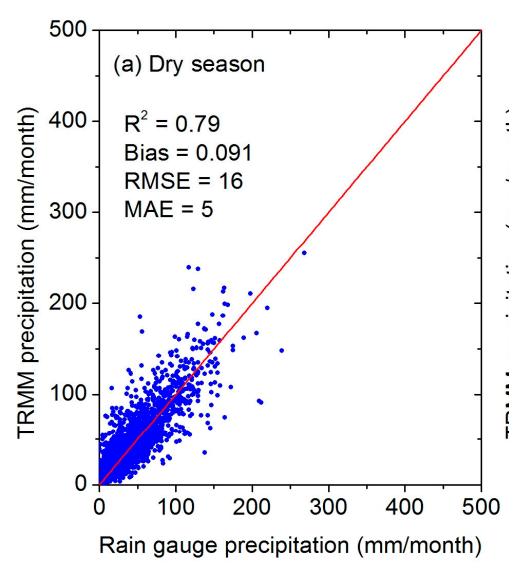

(a)

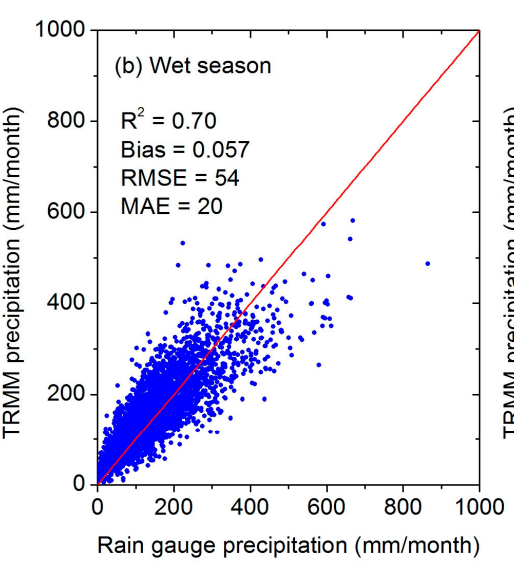

(b)

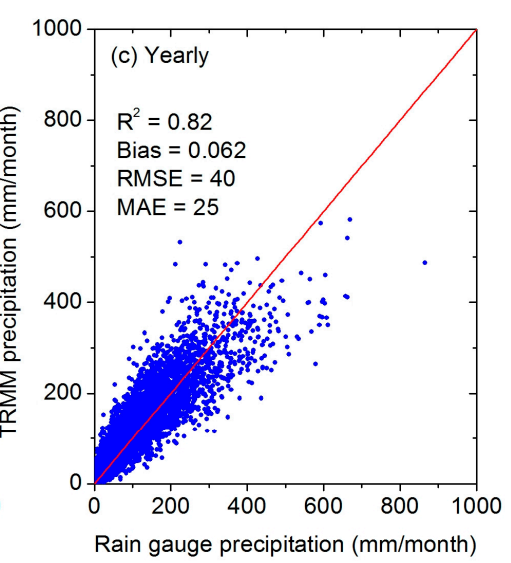

(c)

Figure 5. Comparison of precipitation measured by RGS with the original TRMM 3B43 data at multi-time scales: (a) the dry season; (b) the wet season; and (c) the whole year from 2001 to 2015. The red line indicates a 1:1 correspondence.

\subsection{Performance of the Different Downscaling Models}

Obtaining the regression relationship between the TRMM precipitation and environmental variables, is a vital premise of the downscaling procedure, which directly affects the final result. Therefore, the predictive performances of three regression models (MLR, ANN, and GWR) were evaluated by comparing the predicted annual precipitation by each model with the original TRMM annual precipitation at $0.25^{\circ}$ resolution. To better compare the performance of the three models, a bootstrapping procedure was employed to create a sample of the same size as the original data, a total of 1000 tests were conducted, and performance metrics (i.e., $R^{2}, R M S E, M A E$, and Bias) were calculated accordingly. Table 1 shows the mean values and 95\% confidence interval of $R^{2}, R M S E$, $M A E$, and Bias, estimated by the three models for the three reference years and entire time period. The box plots of $R^{2}$, RMSE, MAE, and Bias are shown in Figure 6. From Table 1 and Figure 6, it can be seen that both ANN and GWR produced a higher $R^{2}$ and lower RMSE and MAE than that of MLR under different climatic conditions. In terms of Bias, the Bias of GWR was lower than that of ANN in three reference years and the entire time period. GWR is a regression algorithm, which adds the geographical information for each location into the regression process, potentially addressing the spatially heterogeneous relationships between various environmental factors. Compared with ANN, GWR can capture more specific, local details. Thus, GWR was chosen as the downscaling model to generate HSPD in subsequent analyses. 

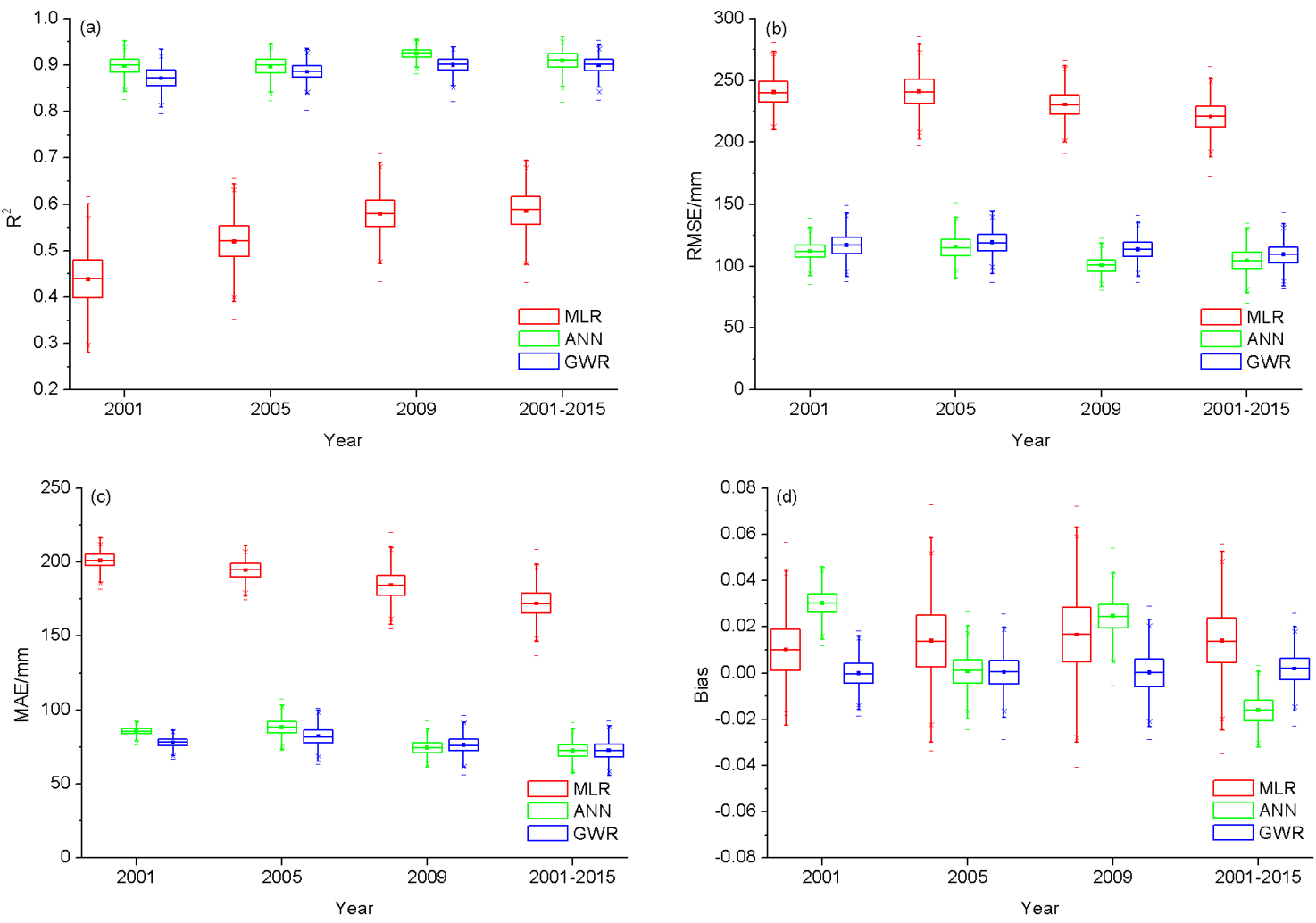

Figure 6. Box plots of performance metrics for different models: (a) $R^{2}$; (b) RMSE; (c) MAE; (d) Bias.

Table 1. Comparison of annual precipitation data from TRMM 3B43 and estimates based on MLR, ANN, and GWR models (95\% confidence intervals are in parentheses).

\begin{tabular}{cccccc}
\hline \multicolumn{2}{c}{ Year } & 2001 (Wet) & 2005 (Normal) & 2009 (Dry) & 2001-2015 (Averaged) \\
\hline \multirow{6}{*}{ MLR } & $R^{2}$ & $0.44(0.32,0.55)$ & $0.52(0.42,0.61)$ & $0.58(0.50,0.66)$ & $0.59(0.49,0.67)$ \\
& RMSE & $241(216,265)$ & $241(214,268)$ & $231(207,255)$ & $221(197,244)$ \\
& MAE & $194(173,215)$ & $185(163,207)$ & $184(165,205)$ & $172(152,192)$ \\
& Bias & $0.010(-0.014,0.038)$ & $0.014(-0.019,0.047)$ & $0.017(-0.022,0.052)$ & $0.014(-0.015,0.043)$ \\
\hline \multirow{6}{*}{ ANN } & $R^{2}$ & $0.90(0.86,0.93)$ & $0.90(0.85,0.93)$ & $0.92(0.90,0.95)$ & $0.91(0.86,0.95)$ \\
& $R M S E$ & $112(97,126)$ & $115(99,134)$ & $101(88,114)$ & $105(85,124)$ \\
& $M A E$ & $85(73,96)$ & $88(78,100)$ & $75(65,85)$ & $73(62,84)$ \\
& Bias & $0.030(0.019,0.042)$ & $0.001(-0.015,0.016)$ & $0.025(0.009,0.041)$ & $-0.016(-0.029,-0.004)$ \\
\multirow{6}{*}{ GWR } & $R^{2}$ & $0.87(0.82,0.91)$ & $0.89(0.85,0.92)$ & $0.90(0.86,0.93)$ & $0.90(0.86,0.93)$ \\
& RMSE & $117(99,137)$ & $119(103,137)$ & $114(97,131)$ & $110(92,127)$ \\
& MAE & $78(66,91)$ & $82(71,96)$ & $76(65,88)$ & $73(61,86)$ \\
& Bias & $-0.000(-0.012,0.012)$ & $0.000(-0.015,0.016)$ & $0.000(-0.017,0.016)$ & $0.002(-0.012,0.016)$ \\
\hline
\end{tabular}

\subsection{Downscaling and Calibrating of TRMM Annual Precipitation}

\subsubsection{Downscaling Analysis of TRMM Annual Precipitation}

The estimated precipitation of three reference years and the entire time period was obtained based on the GWR model. The following took the average annual precipitation of 2001-2015 as an example to analyze the downscaled results. A comparison of Figure 7a,b showed similar spatial patterns of estimated TRMM precipitation when compared with the original TRMM precipitation at a spatial resolution of $0.25^{\circ}$. However, the estimated TRMM precipitation was a little lower than the original TRMM precipitation. In addition, the spatial variability of the estimated TRMM precipitation was higher than that of the original TRMM precipitation, indicating a difference between the estimated TRMM precipitation and the original TRMM precipitation with a $0.25^{\circ}$ spatial resolution in terms 
of precipitation value and spatial distribution range. Figure $7 \mathrm{c}$ shows the spatial distribution of the residual of annual average TRMM precipitation with a spatial resolution of $0.25^{\circ} \times 0.25^{\circ}$. The map of residuals represents the part of the precipitation that could not be explained by the GWR model. Positive values of the residual indicate that the precipitation was underestimated by the GWR method, while negative values indicate an overestimate of precipitation.

(a) Original TRMM precipitation

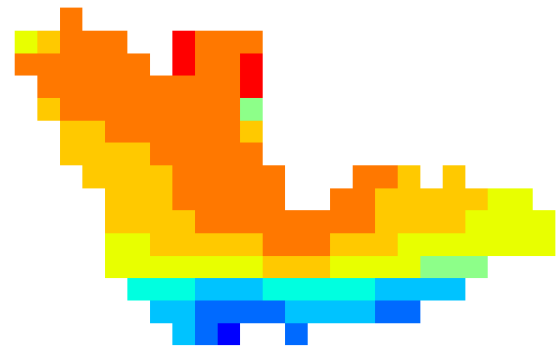

(c) Residual at $0.25^{\circ}$

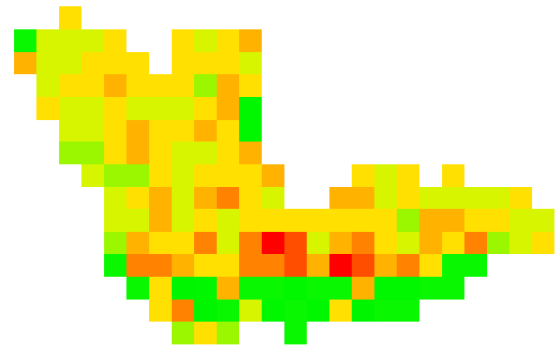

(e) Estimated TRMM precipitation at $1 \mathrm{~km}$

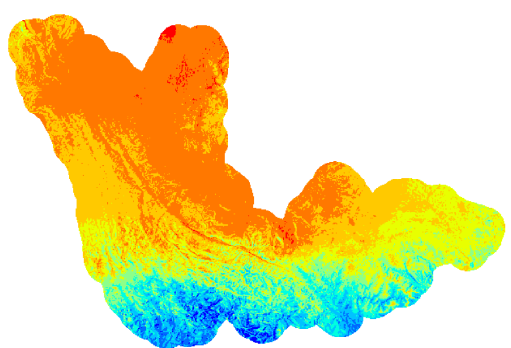

(b) Estimated TRMM precipitation

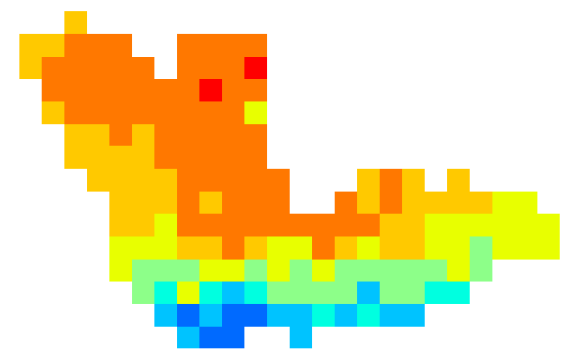

(d) Residual at $1 \mathrm{~km}$

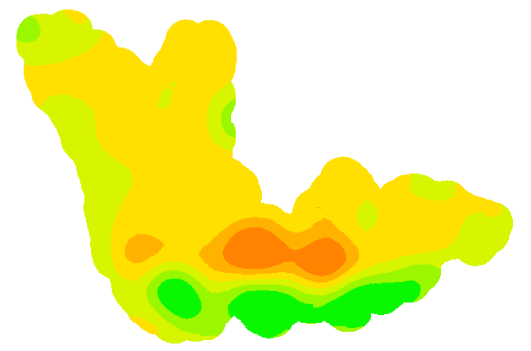

(f) Final downscaled precipitation

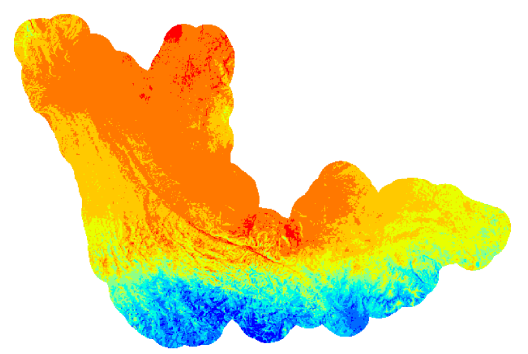

Residual(mm)

$<-300$

$-300--200$

$-200--100$

$-100--50$

$-50-0$

$0-50$

$50-100$

$100-200$

$200-300$

$>300$

Precipitation $(\mathrm{mm})$

$<800$

$800-1000$

$1000-1200$

$1200-1400$

$1400-1600$

$1600-1800$

$1800-2000$

$2000-2200$

工 2200

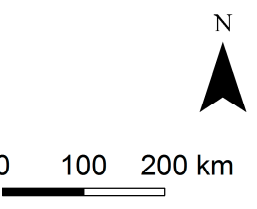

Figure 7. Downscaled results of annual average TRMM precipitation covering a period of 2001-2015: (a) the original TRMM 3B43 precipitation at $0.25^{\circ}$ resolution; (b) the estimated TRMM 3B43 precipitation at $0.25^{\circ}$ resolution by GWR; (c) residual at $0.25^{\circ}$ resolution; (d) residual at $1-\mathrm{km}$ resolution; (e) the estimated TRMM 3B43 precipitation at 1-km resolution; and (f) the final downscaled precipitation map.

Precipitation residuals with a spatial resolution of $0.25^{\circ} \times 0.25^{\circ}$ (Figure 8a) between TRMM precipitation and estimated TRMM precipitation were interpolated to a higher spatial resolution of 1-km using different spatial interpolation methods, i.e., the IDW method in Figure 8b, the simple spline regularized interpolation in Figure $8 c$, the simple spline tension interpolation in Figure $8 d$, the ordinary kriging method in Figure 8e, and the simple kriging method in Figure 8f. Considering the strong influence of different interpolation methods on residual results, we conducted a comparison using LOOCV. The indicators ( $R M S E$ and MAE) of five interpolation methods were compared to select the method with the best performance. According to the results in Table 2, the simple kriging method was accepted for the spatial interpolation of precipitation residuals from lower to higher spatial resolution (Figure 7d). It should be noted that the simple kriging interpolation was used in subsequent analysis such as calibration and monthly fraction disaggregation. 
Figure 7e shows the spatial patterns of the estimated annual average TRMM precipitation with $1-\mathrm{km}$ resolution. Figure $7 \mathrm{f}$ shows the spatial distribution of downscaled annual average TRMM precipitation, which was obtained by adding the high-spatial-resolution predictive annual average precipitation data to the high-spatial-resolution residual obtained above. From Figure 7f, the downscaled TRMM precipitation adequately represented real-world precipitation patterns. In particular, high precipitation was observed mainly in the southern region, and less precipitation was found in the northeast region. Downscaled TRMM precipitation using environmental factors better described the spatial patterns of precipitation with more detail at the spatial resolution of 1-km when compared with the original TRMM precipitation.
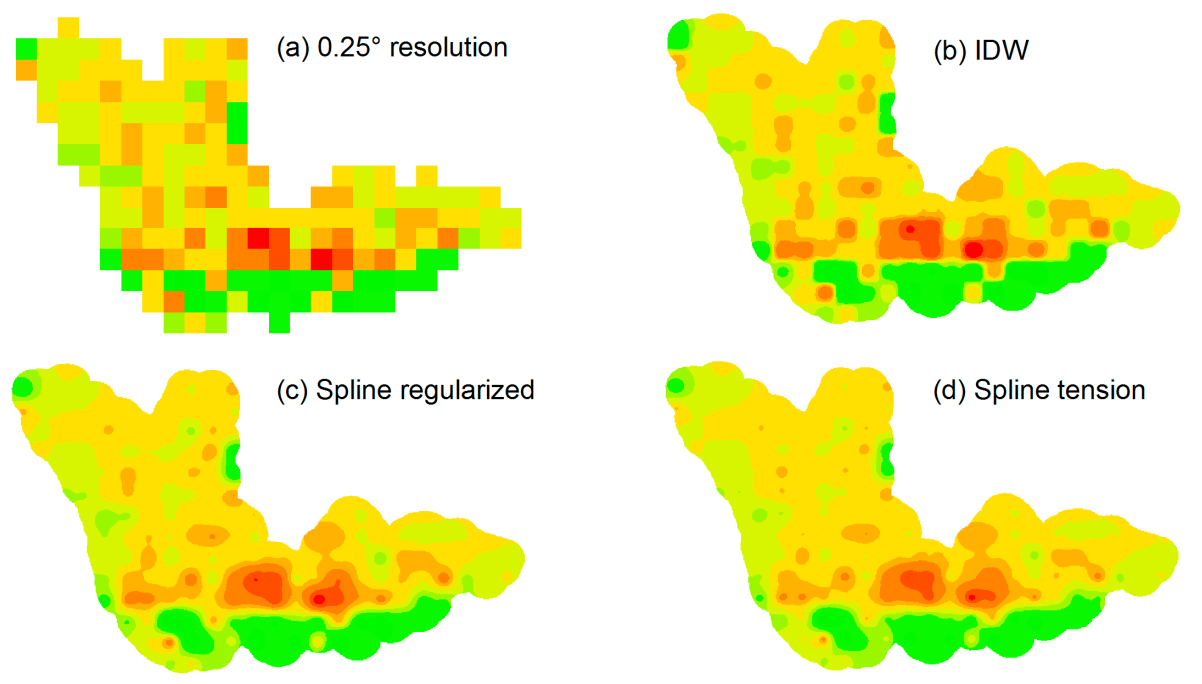

Residual $(\mathrm{mm})$

(e) Ordinary kriging
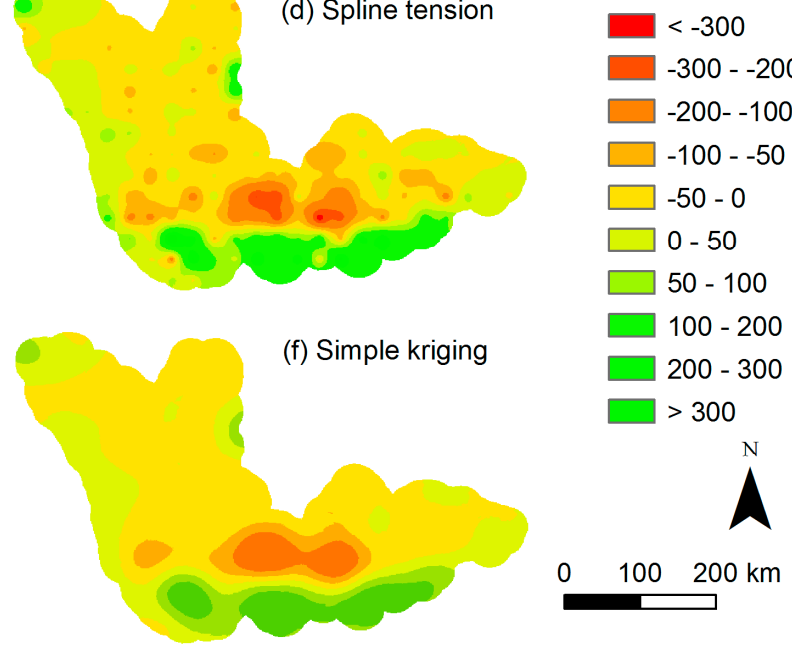

Figure 8. Spatial patterns of precipitation residuals between estimated precipitation by GWR and the TRMM-based precipitation of $0.25^{\circ}$ spatial resolution using different spatial interpolation methods: (a) original grid residual map of $0.25^{\circ}$ resolution; (b) the IDW interpolation method; (c) the simple spline regularized interpolation; (d) the simple spline tension interpolation; (e) the ordinary kriging interpolation method; and (f) the simple kriging interpolation method.

Table 2. Evaluation of different interpolation methods for residual based on GWR model's output (95\% confidence intervals are in parentheses).

\begin{tabular}{cccccc}
\hline $\begin{array}{c}\text { Interpolation } \\
\text { Methods }\end{array}$ & IDW & $\begin{array}{c}\text { Spline } \\
\text { Regularized }\end{array}$ & $\begin{array}{c}\text { Spline } \\
\text { Tension }\end{array}$ & $\begin{array}{c}\text { Ordinary } \\
\text { Kriging }\end{array}$ & $\begin{array}{c}\text { Simple } \\
\text { Kriging }\end{array}$ \\
\hline RMSE & 97.56 & 96.50 & 96.39 & 96.47 & 95.56 \\
& $(83.11,114.26)$ & $(82.10,113.86)$ & $(81.95,113.00)$ & $(82.05,113.28)$ & $(81.23,112.40)$ \\
MAE & 67.89 & 67.73 & 67.48 & 67.45 & 66.86 \\
& $(57.68,78.92)$ & $(57.83,78.62)$ & $(57.35,78.41)$ & $(57.32,78.39)$ & $(56.95,77.77)$ \\
\hline
\end{tabular}




\subsubsection{Calibrating Analysis of Downscaled TRMM Annual Precipitation}

Calibration with rain gauge data is an essential step for the downscaling-calibration procedure as there may be some bias in the downscaled precipitation introduced by the inherent error in the original TRMM precipitation when downscaling [32]. In this study, we employed two calibration methods (GDA and GRA) to correct the bias of the downscaled precipitation data using rainfall data from RGS. The rainfall data from 21 calibration RGS were used to calibrate the downscaled precipitation and the remaining 19 RGS were used for validation. It should be noted that there is the potential for substantial uncertainty in precipitation inferred from gauge observations as gauges in mountainous terrain often suffer significant undercatch errors due to strong winds and accessibility difficulties that can obstruct routine maintenance [71]. In this section, the original TRMM precipitation was labeled as V7 and the above-mentioned downscaled precipitation was labeled as DS. The precipitation after GDA and GRA calibration based on the downscaled precipitation (DS) was labeled as DSGDA and DSGRA, respectively.

The statistical results of V7, DS, DSGDA, and DSGRA using 19 validation RGS measurements for three reference years and the entire time period are listed in Table 3. Compared with the V7 results, the DS results improved accuracy with reduced RMSE and Bias values, and considerable improvement could be observed in the dry year. In general, both the GDA and GRA calibration methods can further improve accuracy with increased $R^{2}$ and reduced RMSE, MA, and Bias values. Compared with the GDA calibration method, GRA performed better in terms of the four indicators calculated. Therefore, the GRA method was used to calibrate the downscaled precipitation on an annual scale. The final calibration results of three reference years and the entire time period were conducted based on 21 calibration RGS, which are shown in Figures 9 and 10. The estimated precipitation for 2001, 2005, 2009, and 2001-2015 were $1544 \mathrm{~mm}, 1320 \mathrm{~mm}, 1068 \mathrm{~mm}$, and $1309 \mathrm{~mm}$, respectively. The spatial distribution and amount variations of precipitation reflected well the wet, normal, and dry conditions. Note that some outliers were identified in Figure 10, which may be attributed to high precipitation in mountainous areas, and may also be partially due to errors in the downscaling process.

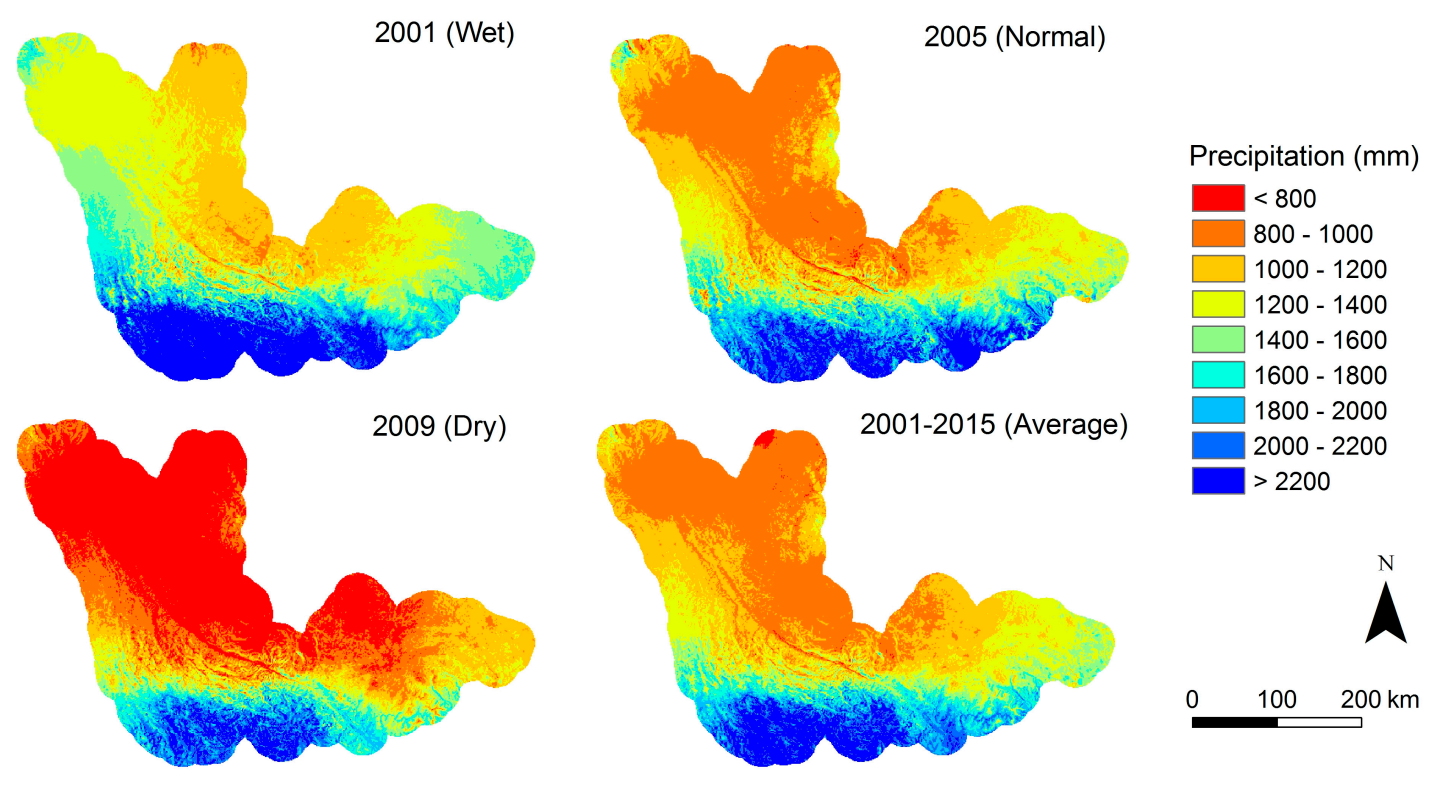

Figure 9. Final calibrated downscaled annual precipitation with 1-km resolution for three reference years and the entire time period. 


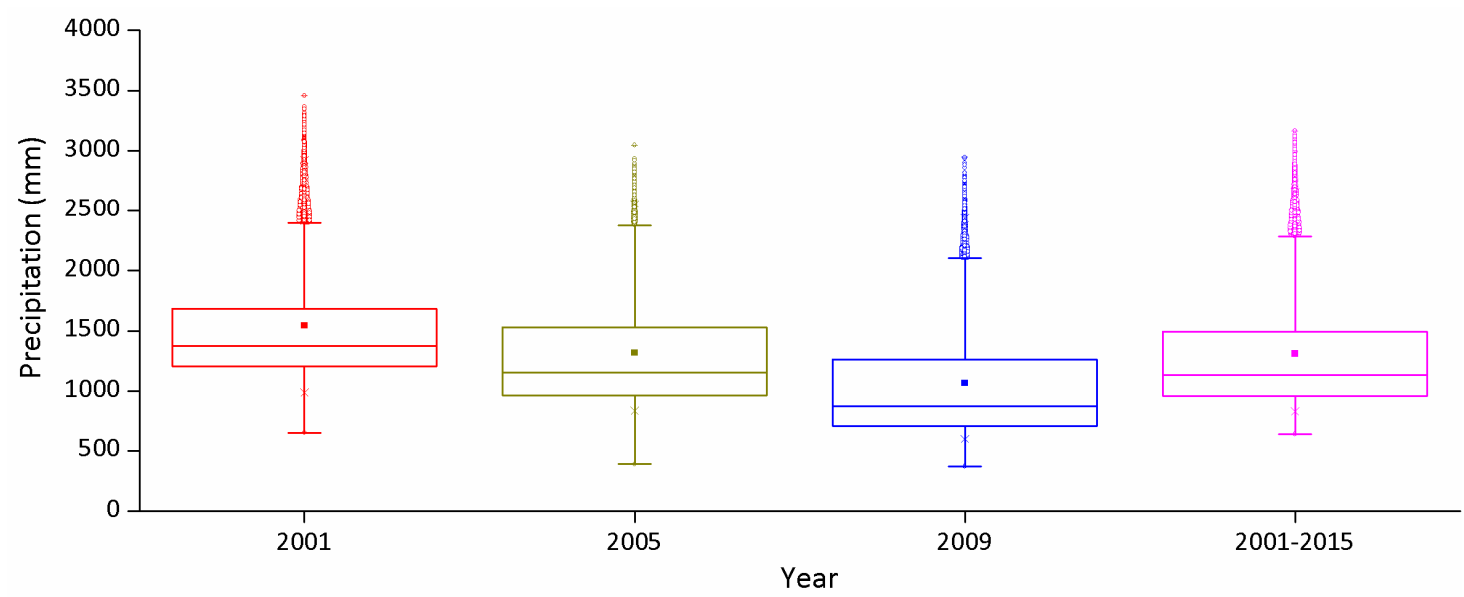

Figure 10. Box plots of downscaled and calibrated annual precipitation for three reference years and the entire time period.

Table 3. Statistics of validation results using 19 validation RGS on an annual scale for three reference years and the entire time period ( $95 \%$ confidence intervals are in parentheses).

\begin{tabular}{|c|c|c|c|c|c|c|}
\hline Year & Datasets & $\begin{array}{l}\text { Mean } \\
(\mathrm{mm})\end{array}$ & $R^{2}$ & $\begin{array}{l}\text { RMSE } \\
(\mathrm{mm})\end{array}$ & $\begin{array}{l}M A E \\
(\mathrm{~mm})\end{array}$ & Bias \\
\hline \multirow{5}{*}{2001 (Wet) } & RGS & 1276 & & & & \\
\hline & V7 & 1210 & $\begin{array}{c}0.36 \\
(0.12,0.65)\end{array}$ & $\begin{array}{c}246 \\
(107,399)\end{array}$ & $\begin{array}{c}159 \\
(82,267)\end{array}$ & $\begin{array}{c}-0.050 \\
(-0.133,0.027)\end{array}$ \\
\hline & DS & 1218 & $\begin{array}{c}0.35 \\
(0.06,0.66)\end{array}$ & $\begin{array}{c}245 \\
(125,354)\end{array}$ & $\begin{array}{c}171 \\
(98,260)\end{array}$ & $\begin{array}{c}-0.044 \\
(-0.125,0.033)\end{array}$ \\
\hline & DSGDA & 1290 & $\begin{array}{c}0.54 \\
(0.21,0.80)\end{array}$ & $\begin{array}{c}198 \\
(125,266)\end{array}$ & $\begin{array}{c}155 \\
(102,217)\end{array}$ & $\begin{array}{c}0.012 \\
(-0.055,0.078)\end{array}$ \\
\hline & DSGRA & 1279 & $\begin{array}{c}0.55 \\
(0.22,0.80)\end{array}$ & $\begin{array}{c}196 \\
(123,264)\end{array}$ & $\begin{array}{c}155 \\
(101,215)\end{array}$ & $\begin{array}{c}0.004 \\
(-0.064,0.070)\end{array}$ \\
\hline \multirow{5}{*}{2005 (Normal) } & RGS & 1035 & & & & \\
\hline & V7 & 951 & $\begin{array}{c}0.57 \\
(0.18,0.87)\end{array}$ & $\begin{array}{c}243 \\
(105,411)\end{array}$ & $\begin{array}{c}156 \\
(82,263)\end{array}$ & $\begin{array}{c}-0.078 \\
(-0.174,0.015)\end{array}$ \\
\hline & DS & 974 & $\begin{array}{c}0.60 \\
(0.06,0.90)\end{array}$ & $\begin{array}{c}211 \\
(127,313)\end{array}$ & $\begin{array}{c}159 \\
(100,230)\end{array}$ & $\begin{array}{c}-0.056 \\
(-0.136,0.031)\end{array}$ \\
\hline & DSGDA & 1053 & $\begin{array}{c}0.66 \\
(0.12,0.92)\end{array}$ & $\begin{array}{c}190 \\
(116,271)\end{array}$ & $\begin{array}{c}142 \\
(88,203)\end{array}$ & $\begin{array}{c}0.020 \\
(-0.060,0.109)\end{array}$ \\
\hline & DSGRA & 1068 & $\begin{array}{c}0.65 \\
(0.14,0.92) \\
\end{array}$ & $\begin{array}{c}185 \\
(115,254) \\
\end{array}$ & $\begin{array}{c}137 \\
(84,198) \\
\end{array}$ & $\begin{array}{c}0.035 \\
(-0.045,0.121) \\
\end{array}$ \\
\hline \multirow{5}{*}{2009 (Dry) } & RGS & 826 & & & & \\
\hline & V7 & 791 & $\begin{array}{c}0.45 \\
(0.12,0.76)\end{array}$ & $\begin{array}{c}235 \\
(153,333)\end{array}$ & $\begin{array}{c}184 \\
(123,255)\end{array}$ & $\begin{array}{c}-0.034 \\
(-0.149,0.097)\end{array}$ \\
\hline & DS & 810 & $\begin{array}{c}0.56 \\
(0.08,0.87)\end{array}$ & $\begin{array}{c}200 \\
(159,239)\end{array}$ & $\begin{array}{c}169 \\
(120,215)\end{array}$ & $\begin{array}{c}-0.015 \\
(-0.112,0.105)\end{array}$ \\
\hline & DSGDA & 831 & $\begin{array}{c}0.62 \\
(0.11,0.89)\end{array}$ & $\begin{array}{c}181 \\
(142,222)\end{array}$ & $\begin{array}{c}157 \\
(117,197)\end{array}$ & $\begin{array}{c}0.010 \\
(-0.088,0.118)\end{array}$ \\
\hline & DSGRA & 828 & $\begin{array}{c}0.63 \\
(0.12,0.90) \\
\end{array}$ & $\begin{array}{c}175 \\
(134,217) \\
\end{array}$ & $\begin{array}{c}151 \\
(111,191) \\
\end{array}$ & $\begin{array}{c}0.006 \\
(-0.087,0.110) \\
\end{array}$ \\
\hline \multirow{5}{*}{ 2001-2015 (Averaged) } & RGS & 1011 & & & & \\
\hline & V7 & 988 & $\begin{array}{c}0.64 \\
(0.37,0.84)\end{array}$ & $\begin{array}{c}202 \\
(111,316)\end{array}$ & $\begin{array}{c}142 \\
(85,220)\end{array}$ & $\begin{array}{c}-0.021 \\
(-0.109,0.073)\end{array}$ \\
\hline & DS & 1005 & $\begin{array}{c}0.63 \\
(0.17,0.89)\end{array}$ & $\begin{array}{c}187 \\
(123,254)\end{array}$ & $\begin{array}{c}144 \\
(91,201)\end{array}$ & $\begin{array}{c}-0.005 \\
(-0.081,0.083)\end{array}$ \\
\hline & DSGDA & 1066 & $\begin{array}{c}0.71 \\
(0.26,0.93)\end{array}$ & $\begin{array}{c}170 \\
(124,211)\end{array}$ & $\begin{array}{c}137 \\
(92,186)\end{array}$ & $\begin{array}{c}0.055 \\
(-0.018,0.139)\end{array}$ \\
\hline & DSGRA & 1061 & $\begin{array}{c}0.72 \\
(0.27,0.93)\end{array}$ & $\begin{array}{c}161 \\
(115,201)\end{array}$ & $\begin{array}{c}128 \\
(83,172)\end{array}$ & $\begin{array}{c}0.050 \\
(-0.017,0.130)\end{array}$ \\
\hline
\end{tabular}




\subsection{Monthly Results of Disaggregating Annual Precipitation}

The previous section demonstrated the best annual precipitation data, which were obtained through downscaling and calibration procedures. The following analysis took the average annual precipitation of 2001-2015 as an example to map the monthly precipitation. The accumulated 1-km resolution annual average precipitation of 2001-2015 was disaggregated into monthly time steps using the fraction specified under Equation (5). The disaggregated 1-km monthly precipitation was labeled as DSdis. The calibration of DSdis was not conducted in this study given that duplicated calibration processes on a monthly scale are no longer necessary after calibration on an annual scale given the scarcity of available RGS [41]. Figure 11 shows the final downscaled monthly precipitation with a 1-km resolution. The spatial distribution changes of downscaled monthly precipitation clearly reflected the influence of monsoon activities (both onset and decline) on precipitation. Meanwhile, the monthly precipitation variations during the wet season (May to October) and the dry season (November to April) are depicted in Figure 12.

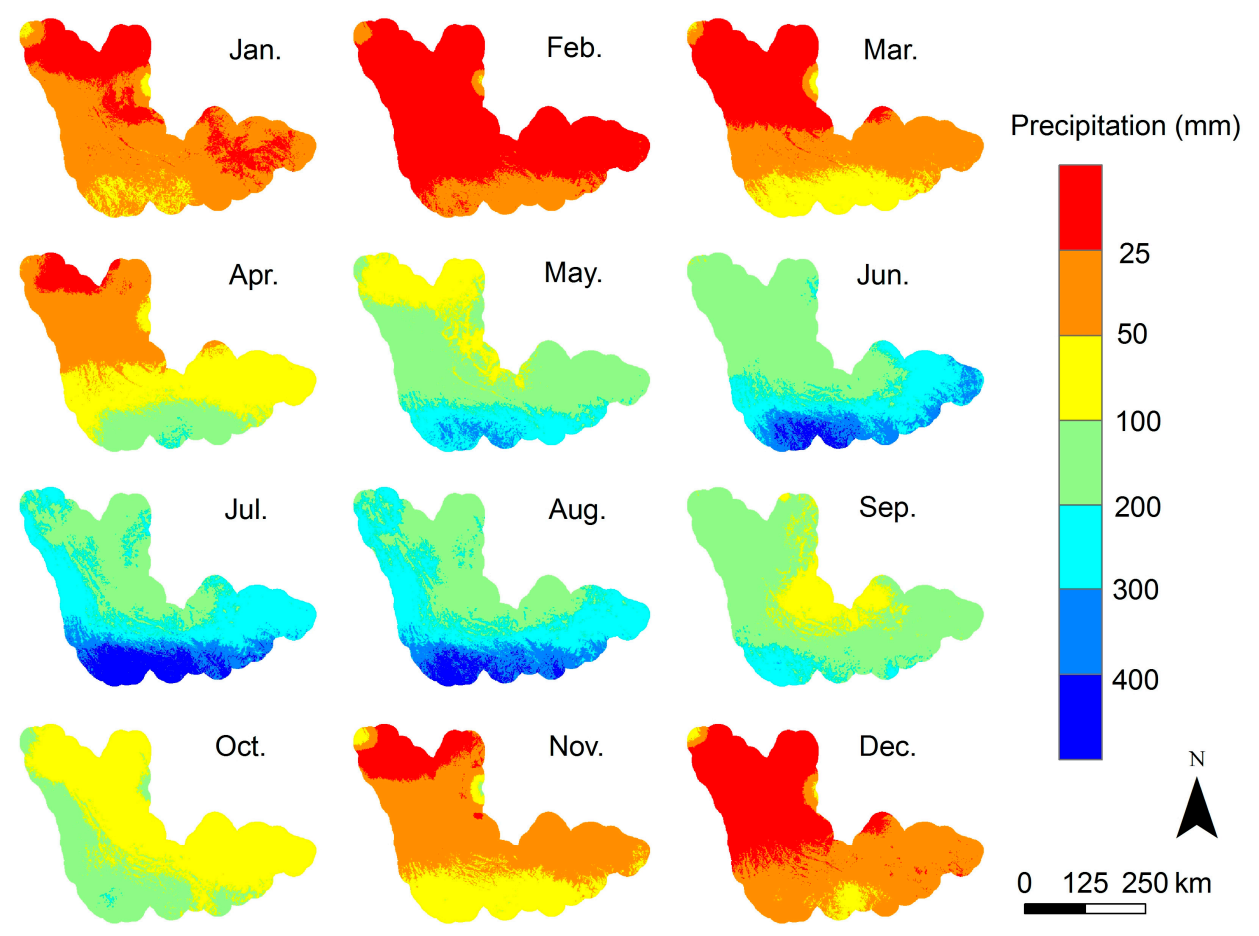

Figure 11. Downscaled average monthly precipitation during 2001-2015 with a 1-km resolution.

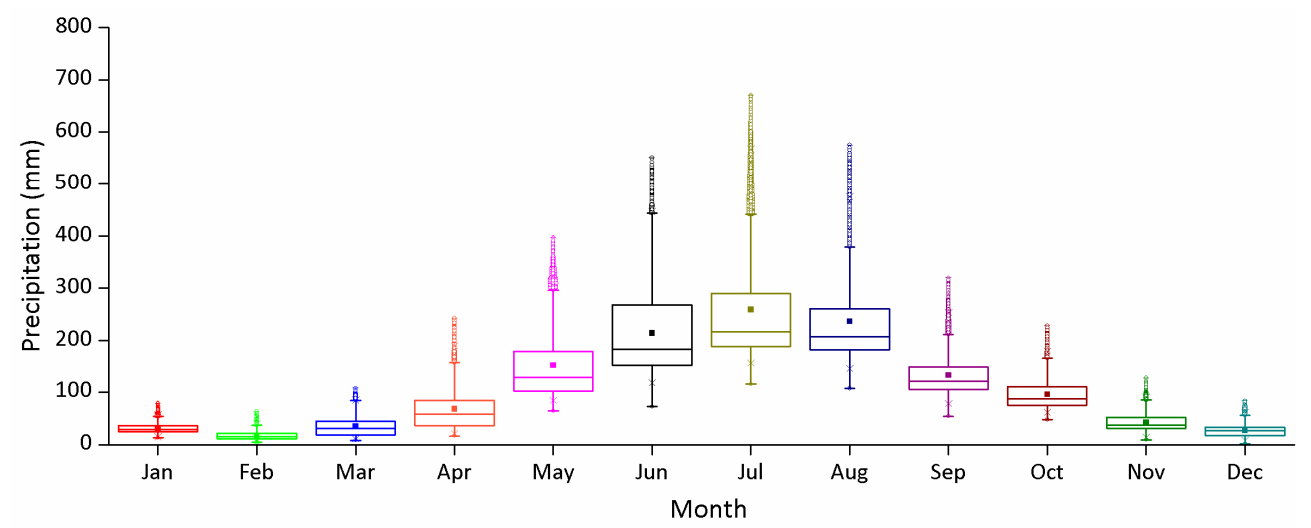

Figure 12. Box plots of downscaled average monthly precipitation during 2001-2015. 
The measurements from validation RGS were also used to assess the accuracy of the downscaled monthly data. The 19 validation RGS were the same as those mentioned in Section 3.3.2. Figure 13a,b compares the monthly precipitation from RGS with the corresponding values from the original TRMM 3B43 data and the downscaled data. The original TRMM 3B43 data could estimate the monthly precipitation with $R^{2}=0.88, R M S E=26.5 \mathrm{~mm}, M A E=13.7 \mathrm{~mm}$, and Bias $=-0.023$. The monthly DSdis data agreed well with the measured data with an $R^{2}$ of $0.91, R M S E$ of $22.2 \mathrm{~mm}$, MAE of $13.5 \mathrm{~mm}$, and Bias of 0.048 . The monthly DSdis data could improve the accuracy further with increased $R^{2}$ and reduced RMSE, but the improvement was not significant with respect to MAE and Bias. Considering the strong seasonality of precipitation in this region, the seasonal bias in the original TRMM data may be introduced into the downscaled monthly precipitation by using the monthly fraction disaggregation method. To explore the effect of the seasonal bias on the downscaled monthly precipitation, we compared monthly precipitation from RGS with the original TRMM data and the downscaled TRMM data in dry and wet seasons, respectively. Figure 13c,e show an underestimation of the original TRMM data in both dry and wet seasons, where the Bias were -0.006 and -0.026 , respectively. The Bias of downscaled monthly precipitation were 0.110 in the dry season and 0.037 in the wet season (Figure 13d,f), which indicate that the downscaled monthly precipitation data in turn overestimated the precipitation in both the dry and wet seasons.

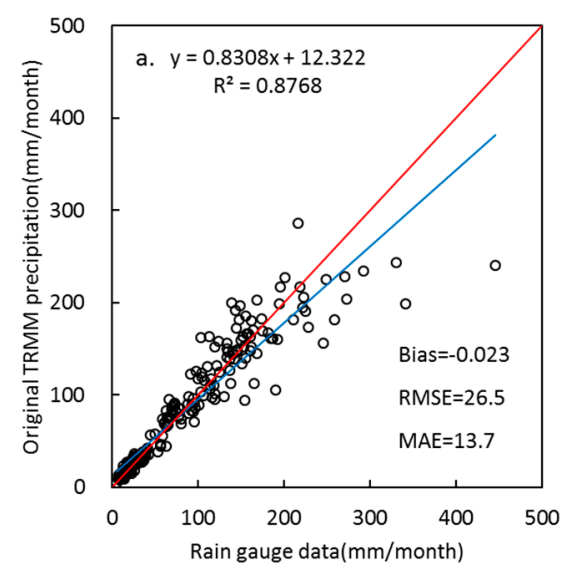

(a)

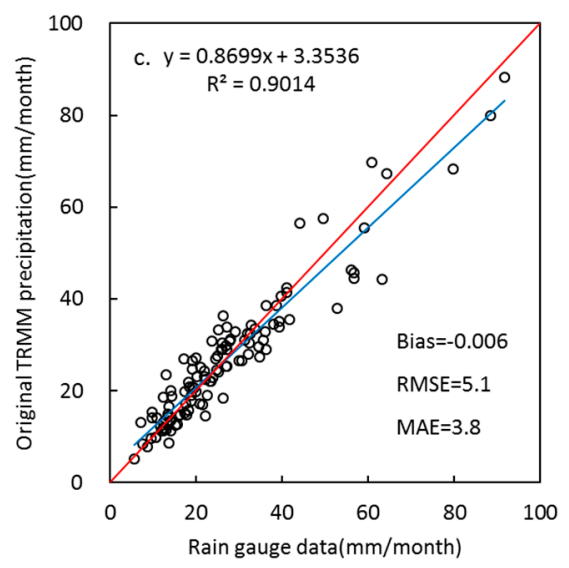

(c)

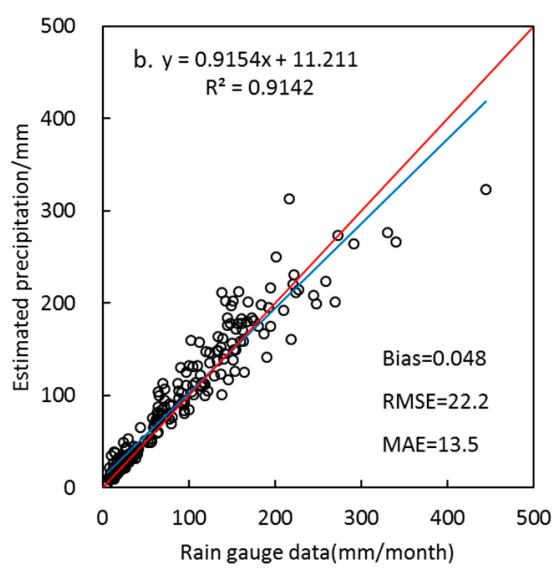

(b)

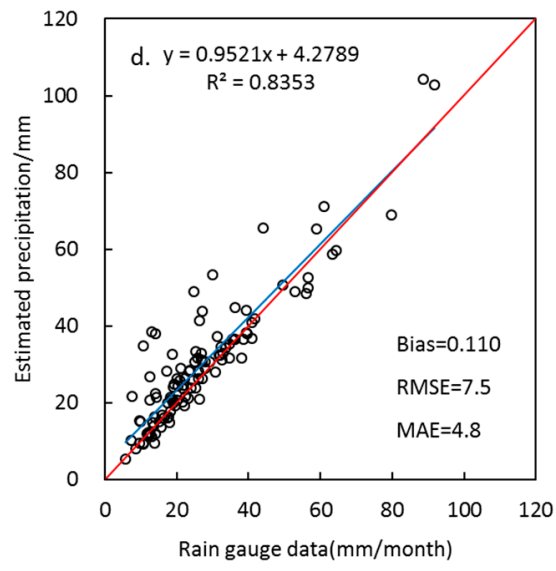

(d)

Figure 13. Cont. 


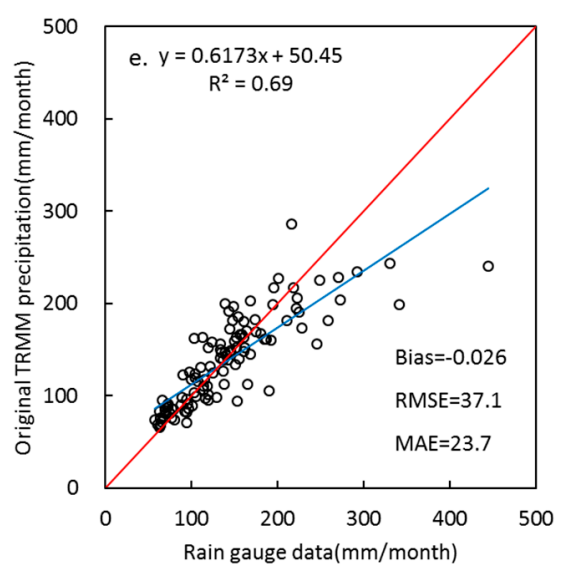

(e)

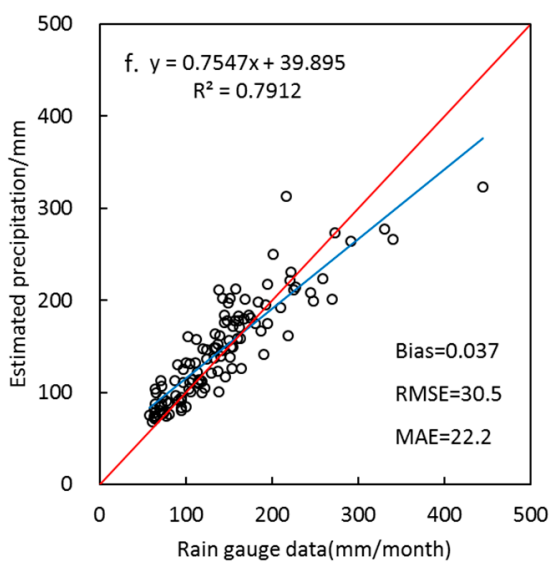

(f)

Figure 13. Comparison of monthly precipitation measured by RGS with (a) original monthly TRMM data; (b) downscaled monthly data; (c) original monthly TRMM data in the dry season; (d) downscaled monthly data in the dry season; (e) original monthly TRMM data in the wet season; and (f) downscaled monthly data in the wet season. The red line indicates a 1:1 correspondence and the blue line gives the linear regression best fit.

\section{Discussion}

\subsection{Sources of Errors and Limitations in the Downscaled Satellite Precipitation Datasets}

The downscaling method is based on the assumption that the regression models established at low spatial resolution can also be used to predict precipitation at a fine resolution with a higher-resolution environmental variables dataset. However, the TRMM product has considerable regional and seasonal errors [72,73]. The errors in TRMM products could seriously disturb the relationship between precipitation and environmental variables at low spatial resolution, making it difficult to accurately predict precipitation with environmental variables at a fine resolution. This limitation can lead to some uncertainty in the downscaled satellite precipitation datasets. Immerzeel et al. [32] pointed out that the downscaled satellite precipitation may be suffering from inherent errors in the satellite precipitation datasets and NDVI caused by orbital drift, atmospheric conditions, and imperfect retrieval algorithms. For example, the purpose of the $3 \mathrm{~B} 43$ algorithm is to produce the best precipitation rate $(\mathrm{mm} / \mathrm{h})$ estimates from TRMM and other data sources. However, there are some deficiencies, such as the discontinuity in the data record and the bias introduced by the AMSU-B algorithm of TRMM 3B43, which potentially reduces the accuracy of TRMM 3B43 [2].

Therefore, calibration with rain gauge data is an essential step to improve the accuracy of the downscaled precipitation data. The GDA and GRA methods have proven to be simple and effective methods to correct the errors in the downscaled data $[41,74,75]$. In this study, calibration using GDA and GRA methods gave better annual precipitation in terms of statistical indicators for the three reference years and the entire time period. GRA was preferred over GDA for the better statistical indicators and some mathematical reasons. Over regions with high spatial variation in precipitation, the downscaled precipitation corrected by ratio-based calibration provided more accurate results than that of difference-based calibration. However, the Red River Basin is a poorly gauged area with 21 rain gauges for calibration present over $76,000 \mathrm{~km}^{2}$ area and, hence, one gauge represents approximately $3619 \mathrm{~km}^{2}$. The scarcity of rain gauge stations inevitably limits the capabilities of the GDA and GRA calibration methods. 


\subsection{Precipitation-NDVI Relationships and Precipitation-Topography Relationships}

The capability of NDVI and DEM for downscaling TRMM precipitation datasets has been widely investigated. The responses of vegetation to precipitation were acknowledged, where NDVI is generally considered as a powerful predictor for precipitation [76,77]. The basic assumption of the regression model is that a significant correlation relationship exists between precipitation and NDVI. Therefore, the impacts of NDVI datasets on the downscaling results included two aspects. First, a higher NDVI did not always represent more precipitation in humid zones because of saturated NDVI $[75,78]$. This saturation effect influences the positive relationship between NDVI and precipitation, which may lead to some errors in the downscaled precipitation datasets. Second, in some local areas, NDVI anomalies induced by the existence of various land use (such as water, wetland, snow, urban, cropland, and barren) [2,79], which disrupt the distribution pattern of the NDVI controlled by precipitation and reduces the predictability of precipitation through NDVI. In this study, these NDVI anomaly pixels were detected and eliminated during data processing. However, the NDVI of these pixels was estimated by interpolating the NDVI of pixels around, which may also lead to some errors in the downscaled precipitation datasets. Generally, unlike topography, vegetation activities cannot be seen as a factor influencing rainfall amounts as precipitation is the driver for vegetation development. Therefore, using NDVI as a predictor in the downscaling process needs to be further studied. For example, a lot of pre-processing was required (i.e., excluding various environments) that considered the vegetation condition of a specific region to make it useful in our analysis.

The orographic effect is believed to be an important mechanism that controls the spatial variability of precipitation in mountainous areas [11]. There are many studies that have highlighted the orographic effect on the spatial variability of rainfall and incorporate topographical features into the downscaling scheme $[2,40,80]$. The key questions in physical process-oriented precipitation mapping are the scale at which topography controls the spatial distribution of precipitation and how this information can be captured. Daly et al. [81] explored this question using six resolutions with a differing smoothing level in the application of PRISM, which is based on station data density and local terrain complexity. Meersmans et al. [34] presented a mean total annual precipitation mapping technique that combined topographical information (i.e., elevation and slope orientation) with average total annual rain gauge data from Belgium where 19 directions and 80 resolutions were considered in this technique to investigate the scale of topographic control at the regional scale. In our study, only a resolution of $1-\mathrm{km}$ (using a pixel averaging method) was taken into consideration, which may have ignored this scale effect. A wider range of resolutions (or smoothing levels) need to be considered to detect the scale of topographic control at a regional scale.

\subsection{The Downscaling Procedure}

Many different geostatistical techniques are used to interpolate precipitation data [82,83]. Recently, several mixed interpolation techniques have been developed, combining kriging and the secondary information $[84,85]$. For example, regression kriging (RK) combines the trend fitted by global regression with the kriged residuals, which makes better use of the available data, thereby improving the accuracy of the estimations when compared to ordinary kriging [86]. The advantage of RK is the ability to extend the method to a broader range of regression techniques and to allow separate interpretation of the two interpolated components [87].

The RK technique has been found useful for downscaling low-resolution precipitation datasets, for example, Wagner et al. [86] considered two covariates (i.e., distance in wind direction from the main orographic barrier and TRMM precipitation) in the regression-based interpolation approaches to evaluate different spatial interpolation schemes for daily rainfall in data scarce regions. Teng et al. [59] established MLR models and the interpolation of residuals in RK where elevation and TRMM were used as auxiliary variables to predict the daily rainfall at a $1 \mathrm{~km} \times 1 \mathrm{~km}$ scale. Park et al. [60] quantified the relationships between the TRMM data and environmental variables based on MLR and gained the residual interpolation by using area-to-point kriging to downscale the TRMM precipitation. 
Although great efforts have been made to advance the downscaling algorithms based on environmental variables, there were still a potential source of errors in downscaling algorithms. The satellite precipitation datasets were predicted using global regression, which had not thoroughly considered that the relationship between precipitation and environmental variables was spatially varying and scale-dependent [49]. For a spatially varying relationship, it may be more appropriate to apply local regression rather than global regression.

Geographically-weighted regression kriging (GWRK) is a hybrid technique and an extension of the GWR approach. GWRK is composed of two components, deterministic and stochastic, where both are modeled separately. The deterministic component is modeled with GWR and uses available covariate information to predict the trend of a target variable. Similar to universal kriging, GWR is a local regression approach that extends the traditional regression framework by allowing the estimation of local, rather than global, parameters. GWR has the advantage of investigating the non-stationary and scale-dependent characteristics of the relationship between the variables $[49,67]$. The stochastic component (residuals) can be interpolated with kriging and added to the estimated trend. Residuals are considered as errors, and it is possible that the errors have some spatial correlation structure that can be modeled. It could be considered that the errors are the component of the model which cannot be explained by the deterministic component, but is important to add as it helps explain the variation of the target variable across space [88]. GWRK has been proven to be an effective method for spatial prediction [88-90]. However, few studies have investigated this approach to downscale the low-resolution satellite-based precipitation datasets.

This study applied the GWRK downscaling algorithm for the TRMM 3B43 precipitation product in Red River Basin, Southwest China, providing a fresh case study for similar research in other mountainous areas. GWRK can provide an alternative to other global models when estimating non-stationarity relationships, especially in precipitation which is highly variable spatially. Despite several limitations with the GWR approach (i.e., smoothing effect) that were found in the previous study [49], the GWRK presented a realistic picture of the spatial distribution of precipitation. Overall, the GWRK explicitly addressed the spatial dependency and represents a new and accurate way of mapping precipitation. Our work also provided a basis for water resources management using a remote sensing data source with a considerable difference of altitudes and uneven spatial distribution of precipitation patterns. However, this approach could not be used to downscale the satellite precipitation datasets over the regions where precipitation has no relationship with NDVI and DEM (such as evergreen vegetation, snow covered areas, desert, and water bodies). The common characteristics of these regions are that there is no vegetation and the precipitation is usually not correlated with the topography. The very weak relationship between the dependent variable and the independent variables would be the detriment of the explanatory and predictive ability of the built regression model [49].

\section{Conclusions}

This paper investigated a geostatistical downscaling-calibration procedure of TRMM 3B43 product, in conjunction with rain gauge data and environmental variables, to map annual and monthly gridded precipitation data at a fine spatial resolution in a mountainous watershed affected by a monsoonal climate. The following conclusions were drawn based on this work:

1. A comparison between the TRMM precipitation and measurements from RGS indicated that good agreement was found between the two datasets. Moreover, TRMM precipitation was 6.2\% higher than observations from RGS at a yearly scale.

2. In the process of downscaling satellite precipitation datasets with environmental variables, it was critical to select a suitable downscaling procedure to effectively conduct the downscaling based on the relationship between satellite precipitation and the NDVI, DEM. In this study, we established a hybrid downscaling method using a regression model with residual correction. According to the comparison of different regression models and residual interpolation methods, 
the GWRK method was accepted to conduct the downscaling of TRMM data. This indicated the non-stationary nature of the precipitation-NDVI and precipitation-DEM relationships and the spatial correlation structure of regression residuals needs to be considered when downscaling satellite precipitation datasets.

3. Calibration with rain gauge data is an essential step for the downscaling-calibration procedure. Both the GDA and GRA calibration provided better annual precipitation when validated based on rain gauge data. The GRA outperformed the GDA method in terms of the validation metrics calculated.

4. Downscaled TRMM precipitation using environmental factors better described the spatial patterns of precipitation with more details at the spatial resolution of 1-km when compared with the original TRMM precipitation. Moreover, the simple disaggregation procedure based on the monthly fractions was practically used to disaggregate annual precipitation to monthly precipitation. The disaggregated 1-km monthly precipitation not only improved the spatial resolution, but also agreed well with rain gauge data (i.e., $R^{2}=0.72, R M S E=161.0 \mathrm{~mm}$, $M A E=127.5 \mathrm{~mm}$, and Bias $=0.050$ for annual downscaled precipitation during 2001-2015; $R^{2}=0.91, R M S E=22.2 \mathrm{~mm}, M A E=13.5 \mathrm{~mm}$, and Bias $=0.048$ for monthly downscaled precipitation during 2001-2015).

This study demonstrated that through integrated downscaling-calibration of satellite precipitation, it is feasible to map fine-resolution annual and monthly precipitation for a mountainous and monsoon-driven watershed. Since the atmospheric variables (e.g., humidity, wind, temperature, etc.) are closely related to precipitation, these variables should be considered to downscale satellite precipitation datasets in the future. In addition, the Integrated Multi-satellitE Retrievals for GPM (IMERG) product is available at finer spatial and temporal scales, which have also been proven to be better than the TRMM product [91,92]. Further investigations should be conducted to examine the potential of the IMERG product for downscaling.

Acknowledgments: This work was funded by the National Key R \& D Program of China (grant 2016YFA0601601) and Applied Basic Research Programs of Yunnan Province (grant 2017FB071). We are very grateful to the editors and anonymous reviewers for their valuable comments, which greatly improved the quality of the paper.

Author Contributions: Yungang Li conceived and designed the study, and Yueyuan Zhang contributed to the writing of the paper. Xuan Ji, Xian Luo, and Xue Li participated in the data processing. All of the authors contributed to editing and reviewing the manuscript.

Conflicts of Interest: The authors declare no conflict of interest.

\section{Abbreviations}

TRMM

NDVI

GWR

MLR

ANN

GDA

GRA

HSPD

IDW

PRISM

OPM

ASOADeK

GPCP

GSMaP

CHIRPS

MSWEP
Tropical Rainfall Measuring Mission

Normalized Difference Vegetation Index

Geographically-weighted regression

Multiple linear regression

Artificial neural network

Geographical difference analysis

Geographical ratio analysis

High-spatial-resolution precipitation data

Inverse distance weighted

Parameter-elevation Regressions on Independent Slopes Model

Orographic Precipitation Model

Auto-Searched Orographic and Atmospheric Effects Detrended Kriging

The Global Precipitation Climatology Project

The Global Satellite Mapping of Precipitation

The Climate Hazards Group InfraRed Precipitation with Station data

The Multi-Source Weighted-Ensemble Precipitation 


$\begin{array}{ll}\text { PERSIANN-CDR } & \text { The Precipitation Estimation from Remotely Sensed Information using Artificial } \\ & \text { Neural Networks-Climate Data Record } \\ \text { GPM } & \text { The Global Precipitation Measurement } \\ \text { NEXRAD } & \text { Next-Generation Radar } \\ \text { DEM } & \text { Digital elevation model } \\ \text { RGS } & \text { Rain gauge stations } \\ \text { NASA } & \text { National Aeronautics and Space Administration } \\ \text { JAXA } & \text { Japan Aerospace Exploration Agency } \\ \text { MODIS } & \text { Terra Moderate Resolution Imaging Spectroradiometer } \\ \text { IGBP } & \text { The International Geosphere Biosphere Program } \\ \text { SRTM } & \text { Shuttle Radar Topographic Mission } \\ \text { MLP } & \text { Multi-layer perceptron } \\ R \text { R } & \text { The coefficient of determination } \\ \text { RMSE } & \text { The root mean square error } \\ M A E & \text { The mean absolute error } \\ \text { LOOCV } & \text { Leave-one-out Cross Validation } \\ \text { RK } & \text { Regression Kriging } \\ \text { GWRK } & \text { Geographically Weighted Regression Kriging } \\ \text { GPCC } & \text { The Global Precipitation Climatology Centre } \\ \text { IMERG } & \text { The Integrated Multi-satellitE Retrievals for GPM } \\ \end{array}$

\section{References}

1. Hu, Q.; Yang, D.; Wang, Y.; Yang, H. Accuracy and spatio-temporal variation of high resolution satellite rainfall estimate over the Ganjiang River Basin. Sci. China Technol. Sci. 2013, 56, 853-865. [CrossRef]

2. Jia, S.; Zhu, W.; Lü, A.; Yan, T. A statistical spatial downscaling algorithm of TRMM precipitation based on NDVI and DEM in the Qaidam Basin of China. Remote Sens. Environ. 2011, 115, 3069-3079. [CrossRef]

3. Li, M.; Shao, Q. An improved statistical approach to merge satellite rainfall estimates and raingauge data. J. Hydrol. 2010, 385, 51-64. [CrossRef]

4. Goodrich, D.; Faurès, J.; Woolhiser, D.; Lane, L.; Sorooshian, S. Measurement and analysis of small-scale convective storm rainfall variability. J. Hydrol. 1995, 173, 283-308. [CrossRef]

5. Goovaerts, P. Geostatistical approaches for incorporating elevation into the spatial interpolation of rainfall. J. Hydrol. 2000, 228, 113-129. [CrossRef]

6. Guo, H.; Bao, A.; Liu, T.; Ndayisaba, F.; He, D.; Kurban, A.; Maeyer, P.D. Meteorological drought analysis in the Lower Mekong Basin using satellite-based long-term CHIRPS product. Sustainability 2017, 9, 901. [CrossRef]

7. Simons, G.; Bastiaanssen, W.; Ngô, L.; Hain, C.; Anderson, M.; Senay, G. Integrating global satellite-derived data products as a pre-analysis for hydrological modelling studies: A case study for the Red River Basin. Remote Sens. 2016, 8, 279. [CrossRef]

8. Grimes, D.I.F.; Diop, M. Satellite-based rainfall estimation for river flow forecasting in Africa. I: Rainfall estimates and hydrological forecasts. Hydrol. Sci. J. 2003, 48, 567-584. [CrossRef]

9. Wheater, H.S.; Isham, V.S.; Cox, D.R.; Chandler, R.E. Spatial-temporal rainfall fields: Modelling and statistical aspects. Hydrol. Earth Syst. Sci. 2000, 4, 581-601. [CrossRef]

10. Xie, P.; Arkin, P.A. Analyses of global monthly precipitation using gauge observations, satellite estimates, and numerical model predictions. J. Clim. 1996, 9, 840-858. [CrossRef]

11. Fang, J.; Du, J.; Xu, W.; Shi, P.; Li, M.; Ming, X. Spatial downscaling of TRMM precipitation data based on the orographical effect and meteorological conditions in a mountainous area. Adv. Water Resour. 2013, 61, 42-50. [CrossRef]

12. Gao, Z.; Long, D.; Tang, G.; Zeng, C.; Huang, J.; Hong, Y. Assessing the potential of satellite-based precipitation estimates for flood frequency analysis in ungauged or poorly gauged tributaries of China's Yangtze River basin. J. Hydrol. 2017, 550, 478-496. [CrossRef]

13. Hutchinson, M.F. The application of thin plate smoothing splines to continent-wide data assimilation. Data Assim. Syst. 1991, 27, 104-113. 
14. Zhang, X.; Srinivasan, R. GIS-based spatial precipitation estimation: A comparison of geostatistical approaches. J. Am. Water Resour. Assoc. 2009, 45, 894-906. [CrossRef]

15. Hans, W. Multivariate Geostatistics: An Introduction with Applications; Springer: Berlin, Germany, 2003.

16. Daly, C.; Neilson, R.P.; Phillips, D.L. A statistical-topographic model for mapping climatological precipitation over mountain terrain. J. Appl. Meteorol. 1994, 33, 140-158. [CrossRef]

17. Shamir, E.; Rimmer, A.; Georgakakos, K.P. The use of an orographic precipitation model to assess the precipitation spatial distribution in Lake Kinneret Watershed. Water 2016, 8, 591. [CrossRef]

18. Guan, H.D.; Wilson, J.L.; Makhnin, O. Geostatistical mapping of mountain precipitation incorporating Autosearched Effects of Terrain and Climatic Characteristic. J. Hydrometeorol. 2005, 6, 1018-1031. [CrossRef]

19. Hong, Y.; Nix, H.A.; Hutchinson, M.F.; Booth, T.H. Spatial interpolation of monthly mean climate data for China. Int. J. Climatol. 2005, 25, 1369-1379. [CrossRef]

20. Mahesh, C.; Prakash, S.; Sathiyamoorthy, V.; Gairola, R.M. Artificial neural network based microwave precipitation estimation using scattering index and polarization corrected temperature. Atmos. Res. 2011, 102, 358-364. [CrossRef]

21. Huffman, G.J.; Adler, R.F.; Arkin, P.; Chang, A.; Ferraro, R.; Gruber, A.; Janowiak, J.; Mcnab, A.; Rudolf, B.; Schneider, U. The Global Precipitation Climatology Project (GPCP) combined precipitation dataset. Bull. Am. Meteorol. Soc. 1997, 78, 5-20. [CrossRef]

22. Kubota, T.; Shige, S.; Hashizume, H.; Aonashi, K.; Takahashi, N.; Seto, S.; Takayabu, Y.N.; Ushio, T.; Nakagawa, K.; Iwanami, K. Global precipitation map using satellite-borne microwave radiometers by the GSMaP project: Production and validation. IEEE Trans. Geosci. Remote Sens. 2007, 45, 2259-2275. [CrossRef]

23. Funk, C.; Peterson, P.; Landsfeld, M.; Pedreros, D.; Verdin, J.; Shukla, S.; Husak, G.; Rowland, J.; Harrison, L.; Hoell, A. The climate hazards infrared precipitation with stations-A new environmental record for monitoring extremes. Sci. Data 2015, 2, 150066. [CrossRef] [PubMed]

24. Beck, H.E.; van Dijk, A.I.J.M.; Levizzani, V.; Schellekens, J.; Miralles, D.G.; Martens, B.; de Roo, A. MSWEP: 3-hourly $0.25^{\circ}$ global gridded precipitation (1979-2015) by merging gauge, satellite, and reanalysis data. Hydrol. Earth Syst. Sci. 2017, 21, 589-615. [CrossRef]

25. Hsu, K.; Gao, X.; Sorooshian, S.; Gupta, H.V. Precipitation estimation from remotely sensed information using artificial neural networks. J. Appl. Meteorol. 1997, 36, 1176-1190. [CrossRef]

26. Kummerow, C.; Barnes, W.; Kozu, T.; Shiue, J.; Simpson, J. The Tropical Rainfall Measuring Mission (TRMM) sensor package. J. Atmos. Ocean. Technol. 1998, 15, 809. [CrossRef]

27. Huffman, G.J.; Adler, R.F.; Bolvin, D.T.; Gu, G.; Nelkin, E.J.; Bowman, K.P.; Hong, Y.; Stocker, E.F.; Wolff, D.B. The TRMM Multisatellite Precipitation Analysis (TMPA): Quasi-global, multiyear, combined-sensor precipitation estimates at fine scales. J. Hydrometeorol. 2007, 8, 38-55. [CrossRef]

28. Hou, A.Y.; Kakar, R.K.; Neeck, S.; Azarbarzin, A.A.; Kummerow, C.D.; Kojima, M.; Oki, R.; Nakamura, K.; Iguchi, T. The Global precipitation measurement mission. Bull. Am. Meteorol. Soc. 2014, 95, 701-722. [CrossRef]

29. Tian, Y.; Peters-Lidard, C.D.; Choudhury, B.J.; Garcia, M. Multitemporal analysis of TRMM-based satellite precipitation products for land data assimilation applications. J. Hydrometeorol. 2007, 8, 1165-1183. [CrossRef]

30. Naumann, G.; Barbosa, P.; Carrao, H.; Singleton, A.; Vogt, J. Monitoring drought conditions and their uncertainties in Africa using TRMM data. J. Appl. Meteorol. Climatol. 2012, 51, 1867-1874. [CrossRef]

31. Wei, W.; Hui, L.; Yang, D.; Khem, S.; Yang, J.; Gao, B.; Peng, X.; Pang, Z. Modelling hydrologic processes in the Mekong River Basin using a distributed model driven by satellite precipitation and rain gauge observations. PLOS ONE 2016, 11, e0152229.

32. Immerzeel, W.W.; Rutten, M.M.; Droogers, P. Spatial downscaling of TRMM precipitation using vegetative response on the Iberian Peninsula. Remote Sens. Environ. 2009, 113, 362-370. [CrossRef]

33. Wang, J.; Georgakakos, K.P. Validation and sensitivities of dynamic precipitation simulation for winter events over the Folsom Lake Watershed: 1964-1999. Mon. Weather Rev. 2003, 133, 3-19. [CrossRef]

34. Meersmans, J.; Van Weverberg, K.; De Baets, S.; De Ridder, F.; Palmer, S.J.; van Wesemael, B.; Quine, T.A. Mapping mean total annual precipitation in Belgium, by investigating the scale of topographic control at the regional scale. J. Hydrol. 2016, 540, 96-105. [CrossRef]

35. Sokol, Z.; Bližňák, V. Areal distribution and precipitation-altitude relationship of heavy short-term precipitation in the Czech Republic in the warm part of the year. Atmos. Res. 2009, 94, 652-662. [CrossRef] 
36. Jing, W.; Yang, Y.; Yue, X.; Zhao, X. A comparison of different regression algorithms for downscaling monthly satellite-based precipitation over North China. Remote Sens. 2016, 8, 835. [CrossRef]

37. Reid, I. The influence of slope aspect on precipitation receipt. Weather 1973, 28, 490-494. [CrossRef]

38. Smith, R.B. The influence of mountains on the atmosphere. Adv. Geophys. 1979, 21, 87-230.

39. Badas, M.G.; Deidda, R.; Piga, E. Orographic influences in rainfall downscaling. Adv. Geosci. 2005, 2, $285-292$. [CrossRef]

40. Guan, H.D.; Wilson, J.L.; Xie, H.J. A cluster-optimizing regression-based approach for precipitation spatial downscaling in mountainous terrain. J. Hydrol. 2009, 375, 578-588. [CrossRef]

41. Duan, Z.; Bastiaanssen, W.G.M. First results from Version 7 TRMM 3B43 precipitation product in combination with a new downscaling-calibration procedure. Remote Sens. Environ. 2013, 131, 1-13. [CrossRef]

42. Jing, W.; Yang, Y.; Yue, X.; Zhao, X. A spatial downscaling algorithm for satellite-based precipitation over the Tibetan Plateau based on NDVI, DEM, and land surface temperature. Remote Sens. 2016, 8, 655. [CrossRef]

43. Duffaut Espinosa, L.A.; Posadas, A.N.; Carbajal, M.; Quiroz, R. Multifractal downscaling of rainfall using normalized difference vegetation index (NDVI) in the Andes Plateau. PLoS ONE 2017, 12, e0168982. [CrossRef] [PubMed]

44. Immerzeel, W.W.; Quiroz, R.A.; De Jong, S.M. Understanding precipitation patterns and land use interaction in Tibet using harmonic analysis of SPOT VGT-S10 NDVI time series. Int. J. Remote Sens. 2005, 26, 2281-2296. [CrossRef]

45. Quiroz, R.; Yarlequé, C.; Posadas, A.; Mares, V.; Immerzeel, W.W. Improving daily rainfall estimation from NDVI using a wavelet transform. Environ. Model. Softw. 2011, 26, 201-209. [CrossRef]

46. Hunink, J.E.; Immerzeel, W.W.; Droogers, P. A high-resolution precipitation 2-step mapping procedure (HiP2P): Development and application to a tropical mountainous area. Remote Sens. Environ. 2014, 140, 179-188. [CrossRef]

47. Alexakis, D.D.; Tsanis, I.K. Comparison of multiple linear regression and artificial neural network models for downscaling TRMM precipitation products using MODIS data. Environ. Earth Sci. 2016, 75, 1077. [CrossRef]

48. Chen, F.; Liu, Y.; Liu, Q.; Li, X. Spatial downscaling of TRMM 3B43 precipitation considering spatial heterogeneity. Int. J. Remote Sens. 2014, 35, 3074-3093. [CrossRef]

49. Xu, S.; Wu, C.; Wang, L.; Gonsamo, A.; Shen, Y.; Niu, Z. A new satellite-based monthly precipitation downscaling algorithm with non-stationary relationship between precipitation and land surface characteristics. Remote Sens. Environ. 2015, 162, 119-140. [CrossRef]

50. Condom, T.; Rau, P.; Espinoza, J.C. Correction of TRMM 3B43 monthly precipitation data over the mountainous areas of Peru during the period 1998-2007. Hydrol. Process. 2011, 25, 1924-1933. [CrossRef]

51. Franchito, S.H.; Rao, V.B.; Vasques, A.C.; Santo, C.M.E.; Conforte, J.C. Validation of TRMM precipitation radar monthly rainfall estimates over Brazil. J. Geophys. Res. Atmos. 2009, 114, 356-360. [CrossRef]

52. Almazroui, M. Calibration of TRMM rainfall climatology over Saudi Arabia during 1998-2009. Atmos. Res. 2011, 99, 400-414. [CrossRef]

53. Cheema, M.J.M.; Bastiaanssen, W.G.M. Local calibration of remotely sensed rainfall from the TRMM satellite for different periods and spatial scales in the Indus Basin. Int. J. Remote Sens. 2012, 33, 2603-2627. [CrossRef]

54. Li, Y.G.; He, D.M.; Ye, C.Q. Spatial and temporal variation of runoff of Red River Basin in Yunnan. J. Geogr. Sci. 2008, 18, 308-318. [CrossRef]

55. Li, Y.G.; He, D.M. The spatial and temporal variation of NDVI and its relationships to the climatic factors in Red River Basin. J. Mt. Sci. 2009, 27, 333-340. (In Chinese)

56. Zhou, X.; Ni, G.H.; Shen, C.; Sun, T. Remapping annual precipitation in mountainous areas based on vegetation patterns: A case study in the Nu River basin. Hydrol. Earth Syst. Sci. 2017, 21, 999-1015. [CrossRef]

57. Caúla, R.H.; Oliveira-Júnior, J.F.; Gois, G.; Delgado, R.C.; Pimentel, L.C.G.; Teodoro, P.E. Nonparametric statistics applied to fire foci obtained by meteorological satellites and their relationship to the MCD12Q1 product in the state of Rio de Janeiro, Southeast-Brazil. Land Degrad. Dev. 2017, 28, 1056-1067. [CrossRef]

58. Rodríguez, E.; Morris, C.S.; Belz, J.E. A global assessment of the SRTM performance. Photogramm. Eng. Remote Sens. 2006, 72, 249-260. [CrossRef]

59. Teng, H.; Shi, Z.; Ma, Z.; Li, Y. Estimating spatially downscaled rainfall by regression kriging using TRMM precipitation and elevation in Zhejiang Province, southeast China. Int. J. Remote Sens. 2014, 35, 7775-7794. [CrossRef] 
60. Park, N.-W. Spatial downscaling of TRMM precipitation using geostatistics and fine scale environmental variables. Adv. Meteorol. 2013, 2013, 1-9. [CrossRef]

61. Naoum, S.; Tsanis, I.K. Temporal and spatial variation of annual rainfall on the island of Crete, Greece. Hydrol. Process. 2003, 17, 1899-1922. [CrossRef]

62. Lees, B.G. Neural network applications in the geosciences: An introduction. Comput. Geosci. 1996, 22, 955-957. [CrossRef]

63. Tomassetti, B.; Verdecchia, M.; Giorgi, F. NN5: A neural network based approach for the downscaling of precipitation fields-Model description and preliminary results. J. Hydrol. 2009, 367, 14-26. [CrossRef]

64. Kumar, R.; Gairola, R.M.; Sarkar, A.; Agarwal, V.K. Rainfall retrieval from TRMM radiometric channels using artificial neural networks. Indian J. Radio Space Phys. 2007, 36, 114-127.

65. Nielsen, R.H. Counterpropagation networks. Appl. Opt. 1987, 26, 4979-4984. [CrossRef] [PubMed]

66. The MathWorks, Inc. MATLAB and Neural Network Toolbox Release R2012a; The MathWorks, Inc.: Natick, MA, USA, 2012.

67. Foody, G.M. Geographical weighting as a further refinement to regression modelling: An example focused on the NDVI-Rainfall relationship. Remote Sens. Environ. 2003, 88, 283-293. [CrossRef]

68. Fotheringham, A.S.; Brunsdon, C.; Charlton, M. Geographically Weighted Regression: The Analysis of Spatially Varying Relationships; Wiley: New York, NY, USA, 2002.

69. Gao, Y.; Huang, J.; Li, S.; Li, S. Spatial pattern of non-stationarity and scale-dependent relationships between NDVI and climatic factors-A case study in Qinghai-Tibet Plateau, China. Ecol. Indic. 2012, 20, 170-176. [CrossRef]

70. Lloyd, C.D. Assessing the effect of integrating elevation data into the estimation of monthly precipitation in Great Britain. J. Hydrol. 2005, 308, 128-150. [CrossRef]

71. Sieck, L.C.; Burges, S.J.; Steiner, M. Challenges in obtaining reliable measurements of point rainfall. Water Resour. Res. 2007, 43. [CrossRef]

72. Maggioni, V.; Meyers, P.C.; Robinson, M.D. A review of merged high-resolution satellite precipitation product accuracy during the Tropical Rainfall Measuring Mission (TRMM) era. J. Hydrom. 2016, 17, 1101-1117. [CrossRef]

73. Prakash, S.; Mitra, A.K.; AghaKouchak, A.; Pai, D.S. Error characterization of TRMM Multisatellite Precipitation Analysis (TMPA-3B42) products over India for different seasons. J. Hydrol. 2015, 529, 1302-1312. [CrossRef]

74. Zhang, Q.; Shi, P.; Singh, V.P.; Fan, K.; Huang, J. Spatial downscaling of TRMM-based precipitation data using vegetative response in Xinjiang, China. Int. J. Climatol. 2016, 37, 3895-3909. [CrossRef]

75. Shi, Y.; Song, L. Spatial downscaling of monthly TRMM precipitation based on EVI and other geospatial variables over the Tibetan Plateau from 2001 to 2012. Mt. Res. Dev. 2015, 35, 180-194. [CrossRef]

76. Wang, J.; Price, K.P.; Rich, P.M. Spatial patterns of NDVI in response to precipitation and temperature in the central Great Plains. Int. J. Remote Sens. 2001, 22, 3827-3844. [CrossRef]

77. Barbosa, H.A.; Kumar, T.V.L. Influence of rainfall variability on the vegetation dynamics over Northeastern Brazil. J. Arid Environ. 2016, 124, 377-387. [CrossRef]

78. Shi, Y.; Song, L.; Xia, Z.; Lin, Y.; Myneni, R.; Choi, S.; Wang, L.; Ni, X.; Lao, C.; Yang, F. Mapping annual precipitation across Mainland China in the period 2001-2010 from TRMM 3B43 product using spatial downscaling approach. Remote Sens. 2015, 7, 5849-5878. [CrossRef]

79. Wang, H.; Chen, A.; Wang, Q.; He, B. Drought dynamics and impacts on vegetation in China from 1982 to 2011. Ecol. Eng. 2015, 75, 303-307. [CrossRef]

80. Prudhomme, C.; Reed, D.W. Mapping extreme rainfall in a mountainous region using geostatistical techniques: A case study in Scotland. Int. J. Climatol. 1999, 19, 1337-1356. [CrossRef]

81. Daly, C. Guidelines for assessing the suitability of spatial climate data sets. Int. J. Climatol. 2006, 26, 707-721. [CrossRef]

82. Moral, F.J. Comparison of different geostatistical approaches to map climate variables: Application to precipitation. Int. J. Climatol. 2010, 30, 620-631. [CrossRef]

83. Bostan, P.A.; Heuvelink, G.B.M.; Akyurek, S.Z. Comparison of regression and kriging techniques for mapping the average annual precipitation of Turkey. Int. J. Appl. Earth Obs. Geoinf. 2012, 19, 115-126. [CrossRef]

84. Li, J.; Heap, A.D. Spatial interpolation methods applied in the environmental sciences: A review. Environ. Model. Softw. 2014, 53, 173-189. [CrossRef] 
85. Pereira, P.; Oliva, M.; Misiune, I. Spatial interpolation of precipitation indexes in Sierra Nevada (Spain): Comparing the performance of some interpolation methods. Theor. Appl. Climatol. 2015, 126, 683-698. [CrossRef]

86. Wagner, P.D.; Fiener, P.; Wilken, F.; Kumar, S.; Schneider, K. Comparison and evaluation of spatial interpolation schemes for daily rainfall in data scarce regions. J. Hydrol. 2012, 464-465, 388-400. [CrossRef]

87. Hengl, T.; Heuvelink, G.B.M.; Rossiter, D.G. About regression-kriging: From equations to case studies. Comput. Geosci. 2007, 33, 1301-1315. [CrossRef]

88. Kumar, S.; Lal, R.; Liu, D. A geographically weighted regression kriging approach for mapping soil organic carbon stock. Geoderma 2012, 189-190, 627-634. [CrossRef]

89. Harris, P.; Fotheringham, A.S.; Crespo, R.; Charlton, M. The use of geographically weighted regression for spatial prediction: An evaluation of models using simulated data sets. Math. Geosci. 2010, 42, 657-680. [CrossRef]

90. Imran, M.; Stein, A.; Zurita-Milla, R. Using geographically weighted regression kriging for crop yield mapping in West Africa. Int. J. Geogr. Inf. Sci. 2015, 29, 234-257. [CrossRef]

91. Zhao, H.; Yang, B.; Yang, S.; Huang, Y.; Dong, G.; Bai, J.; Wang, Z. Systematical estimation of GPM-based global satellite mapping of precipitation products over China. Atmos. Res. 2018, 201, 206-217. [CrossRef]

92. Prakash, S.; Mitra, A.K.; AghaKouchak, A.; Liu, Z.; Norouzi, H.; Pai, D.S. A preliminary assessment of GPM-based multi-satellite precipitation estimates over a monsoon dominated region. J. Hydrol. 2016, 56, 853-865. [CrossRef]

(C) 2018 by the authors. Licensee MDPI, Basel, Switzerland. This article is an open access article distributed under the terms and conditions of the Creative Commons Attribution (CC BY) license (http:/ / creativecommons.org/licenses/by/4.0/). 